Article

\title{
Antimicrobial and Anti-Biofilm Activity of Polymyxin E Alone and in Combination with Probiotic Strains of Bacillus subtilis KATMIRA1933 and Bacillus amyloliquefaciens B-1895 against Clinical Isolates of Selected Acinetobacter spp.: A Preliminary Study
}

\author{
Munaf AL-Dulaimi ${ }^{1}$, Ammar Algburi ${ }^{2,3, * \mathbb{D}}$, Alyaa Abdelhameed ${ }^{2}$, Maria S. Mazanko ${ }^{4}$, Dmitry V. Rudoy ${ }^{4}$ (D) \\ Alexey M. Ermakov ${ }^{(1 D}$ and Michael L. Chikindas $4,5,6$ (D)
}

check for

updates

Citation: AL-Dulaimi, M.; Algburi, A.; Abdelhameed, A.; Mazanko, M.S.; Rudoy, D.V.; Ermakov, A.M.; Chikindas, M.L. Antimicrobial and Anti-Biofilm Activity of Polymyxin E Alone and in Combination with Probiotic Strains of Bacillus subtilis KATMIRA1933 and Bacillus amyloliquefaciens B-1895 against Clinical Isolates of Selected Acinetobacter spp.: A Preliminary Study. Pathogens 2021, 10, 1574. https: / / doi.org/10.3390/ pathogens 10121574

Academic Editors: Lawrence

S. Young, Kidon Sung, Saeed Khan and Juhee Ahn

Received: 4 November 2021 Accepted: 29 November 2021 Published: 2 December 2021

Publisher's Note: MDPI stays neutral with regard to jurisdictional claims in published maps and institutional affiliations.

Copyright: (c) 2021 by the authors. Licensee MDPI, Basel, Switzerland. This article is an open access article distributed under the terms and conditions of the Creative Commons Attribution (CC BY) license (https:// creativecommons.org/licenses/by/ $4.0 /)$.
1 Educational Laboratories, Baqubah General Hospital, Baqubah 32001, Iraq; munafthamer2233@gmail.com

2 Scholarship and Cultural Relations Department, University of Diyala, Baqubah 32001, Iraq; alyaa.maen@uodiyala.edu.iq

3 Biotechnology Department, College of Science, University of Diyala, Baqubah 32001, Iraq

4 Center for Agrobiotechnology, Don State Technical University, 344002 Rostov-on-Don, Russia; mary.bio@list.ru (M.S.M.); dmitriyrudoi@gmail.com (D.V.R.); amermakov@yandex.ru (A.M.E.); tchikind@sebs.rutgers.edu (M.L.C.)

5 Health Promoting Naturals Laboratory, School of Environmental and Biological Sciences, Rutgers State University, New Brunswick, NJ 08904, USA

6 Department of General Hygiene, I.M. Sechenov First Moscow State Medical University, 119146 Moscow, Russia

* Correspondence: ammar.algburi@gmail.com; Tel.: +964-77052-07111

\begin{abstract}
Acinetobacter spp., the nosocomial pathogen, forms strong biofilms and is resistant to numerous antibiotics, causing persistent infections. This study investigates the antibacterial and anti-biofilm activity of polymyxin E alone and in combination with the cell-free supernatants (CFS) of the tested probiotic bacilli, Bacillus subtilis KATMIRA1933 and Bacillus amyloliquefaciens B-1895 against the selected Acinetobacter spp. starins. Three isolates of Acinetobacter spp., designated as Acinetobacter spp. isolate 1; Acinetobacter spp. isolate 2, and Acinetobacter spp. isolate 3, were collected from patients with burns, wounds, and blood infections, respectively. Bacterial identification and antibiotic susceptibility testing were conducted using the VITEK2 system. Auto-aggregation and coaggregation of the tested bacilli strains with the selected Acinetobacter spp. isolates were evaluated. A disk diffusion assay was used to identify the microorganism's susceptibility to the selected antibiotics, alone and in combination with the CFS of the bacilli. The MIC and MBIC (minimum inhibitory and minimum biofilm inhibitory concentrations) of polymyxin E combined with bacilli CFS were determined. Acinetobacter spp. isolates were (i) sensitive to polymyxin E, (ii) able to form a strong biofilm, and (iii) resistant to the tested antibiotics and the CFS of tested bacilli. Significant inhibition of biofilm formation was noticed when CFS of the tested bacilli were combined with polymyxin E. The bacilli CFS showed synergy with polymyxin E against planktonic cells and biofilms of the isolated pathogens.
\end{abstract}

Keywords: polymyxin E; CFS; spore-forming bacilli; antimicrobial combination; selected Acinetobacter spp. strain

\section{Introduction}

Acinetobacter spp. is a Gram-negative, obligate aerobe, cocco-bacilli, and one of the most prevalent causative agents of several hospital and community-acquired infections [1]. This bacterium is related to skin, soft tissue, and urinary tract infections, in addition to 
meningitis, bacteremia, and pneumonia [2]. Acinetobacter spp. is one of the multidrugresistant (MDR) ESKAPE pathogens, which include Escherichia coli, Staphylococcus aureus, Klebseilla pneumoniae, Acinetobacter baumannii, Pseudomonas aeruginosa, and Enterococcus faecalis [3].

Acinetobacter spp. cells have three main mechanisms of antibiotics resistance: they (i) produce antibiotic-hydrolyzing enzymes, (ii) interrupt binding of antibiotics to the target site of a bacterial cell, and (iii) alternate their target site or modify their cellular functions to avoid an antibiotics' activity [4]. Furthermore, biofilm formation by Acinetobacter spp. is the most important virulence factor, playing an important role in bacterial survival, infection, and antibiotic resistance [3,5].

The "old generation" of antibiotics, such as polymyxins, are commonly used as the drugs of choice to eliminate Acinetobacter infections [6]. Polymyxin E (or colistin) has recently been used as a "last line" therapeutic substance to control the growth of multidrug resistant Gram-negative bacteria [7]. Polymyxin E, a cationic antimicrobial peptide, interacts with the lipid A moiety of bacterial lipopolysaccharides (LPS) and eventually disrupts the outer membrane of bacterial pathogens [8]. However, monotherapy has been reported as a less effective protocol compared to antimicrobial combinations, which are recommended by the National Institutes of Health (NIH) as a potential integrative therapeutic option [9]. Therefore, effective approaches using antimicrobial combinations are urgently required as alternative and safe strategies to combat bacterial resistance to antibiotics. One of the suggested methods is using probiotics and their metabolites as antimicrobial substances in combination with conventional antibiotics to increase the sensitivity of pathogenic strains [10].

Probiotics are live microorganisms that provide health benefits when administered in appropriate amounts [11]. Probiotics play a key role in the regulation of the host immune system by stimulating cytokine production and cellular activity and inhibiting the clustering of pathogens [12]. In addition, the therapeutic properties of probiotics can be attributed to the production of a variety of antibacterial agents, such as short-chain fatty acids, organic acids, ethanol, hydrogen peroxide, and bacteriocins [13].

The combination of polymyxin $E$ with other antibiotics, which is widely used by physicians in critical patients, is reported to have a synergistic effect [6]. These combinations have several advantages, such as (i) using lower concentrations of antimicrobials with greater activity, (ii) reducing their cost, and (iii) limiting toxic side effects (nephrotoxicity and neurotoxicity) [10]. This study aimed to evaluate, in vitro, the antibacterial and anti-biofilm activities of the tested probiotic bacilli and their cell-free supernatants (CFS) alone and in combination with polymyxin E against selected Acinetobacter spp. strains. In addition, we demonstrated the coaggregation potential of probiotic strains with the Acinetobacter spp. isolates.

\section{Results}

\subsection{Bacterial Isolation and Identification}

This study identified three isolates of the selected Acinetobacter spp. in samples taken from hospitalized patients with blood, burn, or wound infections. The clinical isolates grown on blood agar were small, smooth, opaque, raised, creamy, non-hemolytic colonies. On MacConkey agar, the bacterial colonies were pale pinkish, with small size and regular edges. All isolates were grown at 37 and $44{ }^{\circ} \mathrm{C}$, as required. The tested isolates were positive for catalase production and the Simmons citrate test but variable regarding urease production. They were negative to oxidase, Voges-Proskauer, methyl red, and indole production tests. Due to their inability to ferment sugars, their growth on Triple SugarIron (TSI) agar was alkaline with no gases production. The isolates showed no lactose fermentation on the MacConkey agar plate. 


\subsection{Bacterial Identification and Antibiotic Susceptibility Using VITEK 2 System}

Bacterial identification was confirmed by using a Gram-negative Identification (GN-ID) card. The sensitivity of the VITEK 2 system showed that clinical isolates were $97-99 \%$ Acinetobacter spp. which was in agreement with the phenotypic and initial biochemical characteristics described earlier. In addition, to confirm bacterial identification, the VITEK 2 system was used to evaluate the antibiotic susceptibility of the selected Acinetobacter spp. strains using an antibiotics susceptibility Gram-negative (AST-GN) card. In this method, 18 antimicrobial agents were evaluated against the Acinetobacter spp. isolates. We reported that the isolated pathogens were highly tolerant to most of the tested antibiotics. The three isolates were tolerant to 11 tested antibiotics, while two Acinetobacter spp. isolates 1 and 2 were tolerant to trimethoprim-sulfamethoxazole, gentamicin, tobramycin, imipenem, and amikacin. Acinetobacter spp. isolates 2 and 3 were sensitive to tigecycline and minocycline, while all the isolates were sensitive to polymyxin E. Our findings showed that the three isolates were susceptible to polymyxin E. Only Acinetobacter spp. isolate 1 was resistant to tigecycline and minocycline. In regard to trimethoprim/sulfamethoxazole, we noticed that only Acinetobacter spp. isolate 3 was inhibited. Fluoroquinolones resistance was reported in the three selected isolates of Acinetobacter spp. Our findings showed that Acinetobacter spp. isolates 1 and 2 were resistant to amikacin, gentamicin, and tobramycin (Table 1).

Table 1. Resistance rate of selected Acinetobacter spp. isolates to the selected antibiotics.

\begin{tabular}{|c|c|c|}
\hline Antibiotics Family & Antibiotics Type & $\begin{array}{l}\text { Resistant Isolates } \\
\text { No. and \% }\end{array}$ \\
\hline Penicillins & Ampicillin & Acinetobacter spp. isolates 1,2 , and 3 \\
\hline B-lactam inhibitors & Piperacillin/Tazobactam & Acinetobacter spp. isolates 1,2 , and 3 \\
\hline Cephalosporins & $\begin{array}{l}\text { Cefazolin } \\
\text { Cefoxitin } \\
\text { Ceftazidime } \\
\text { Ceftriaxone } \\
\text { Cefepime }\end{array}$ & $\begin{array}{l}\text { Acinetobacter spp. isolates 1, 2, and } 3 \\
\text { Acinetobacter spp. isolates 1, 2, and } 3 \\
\text { Acinetobacter spp. isolates 1, 2, and } 3 \\
\text { Acinetobacter spp. isolates 1, 2, and } 3 \\
\text { Acinetobacter spp. isolates 1, 2, and } 3\end{array}$ \\
\hline Carbapenems & $\begin{array}{l}\text { Imipenem } \\
\text { Meropenem }\end{array}$ & $\begin{array}{l}\text { Acinetobacter spp. isolates 1, 2, and } 3 \\
\text { Acinetobacter spp. isolates 1, 2, and } 3\end{array}$ \\
\hline Aminoglycosides & $\begin{array}{l}\text { Amikacin } \\
\text { Gentamicin } \\
\text { Tobramycin }\end{array}$ & $\begin{array}{l}\text { Acinetobacter spp. isolates } 1 \text { and } 2 \\
\text { Acinetobacter spp. isolates } 1 \text { and } 2 \\
\text { Acinetobacter spp. isolates } 1 \text { and } 2\end{array}$ \\
\hline \multirow[t]{2}{*}{ Tetracyclines } & Tigecycline & Acinetobacter spp. isolate 1 \\
\hline & Minocycline & Acinetobacter spp. isolate 1 \\
\hline Fluoroquinolones & $\begin{array}{l}\text { Ciprofloxacin } \\
\text { Levofloxacin }\end{array}$ & $\begin{array}{l}\text { Acinetobacter spp. isolates 1, 2, and } 3 \\
\text { Acinetobacter spp. isolates 1, 2, and } 3\end{array}$ \\
\hline Folate pathway antagonists & $\begin{array}{l}\text { Trimethoprim } \\
\text { /sulfamethoxazole }\end{array}$ & Acinetobacter spp. isolates 1 and 2 \\
\hline Lipopeptides & Polymyxin E & None \\
\hline
\end{tabular}

\subsection{Probiotic Strains Were Tolerant to Polymyxin E}

In this study, six antibiotics were evaluated against the tested bacilli strains using the disc diffusion method (Kirby-Bauer). Our findings showed that bacilli strains were susceptible to the majority of the selected antibiotics (Table 2), while they were tolerant to polymyxin E. In addition, B. amyloliquefaciens B-1895 showed tolerance to amikacin. Based on the above-mentioned data, polymyxin E was selected in this study to be used alone and in combination with the probiotics CFS to identify the nature of antimicrobial interactions against the selected Acinetobacter spp. strains. 
Table 2. Antibiotic susceptibility of probiotic strains.

\begin{tabular}{|c|c|c|c|c|c|c|}
\hline \multirow{2}{*}{ Probiotic Strains } & \multicolumn{6}{|c|}{ The Average Diameters of Inhibition Zone around Antibiotic Discs (mm) } \\
\hline & $\mathrm{AK}^{*}$ & PME * & FOX * & CTX* & MEM * & TS * \\
\hline $\begin{array}{l}\text { Bacillus subtilis } \\
\text { KATMIRA1933 }\end{array}$ & 22 & zero & 35 & 40 & 37 & 37 \\
\hline $\begin{array}{c}\text { Bacillus amyloliquefaciens } \\
\text { B-1895 }\end{array}$ & 14 & zero & 28 & 28 & 35 & 30 \\
\hline
\end{tabular}

* (AK) amikacin $30 \mathrm{mg}$, (PME) polymyxin E $25 \mathrm{mg}$, (FOX) cefoxitin $30 \mathrm{mg}$, (CTX) cefotaxime $30 \mathrm{mg}$, (MEM) meropenem $10 \mathrm{mg}$, (TS) trimethoprim-sulfamethoxazole $1.25 / 23.75 \mathrm{mg}$.

\subsection{Minimum Inhibitory Concentrations (MICs)}

The MICs of polymyxin E and the tested probiotic CSF were determined for the selected Acinetobacter spp. isolates 1, 2, and 3 using the broth micro-dilution method. The MICs of polymyxin E were $3.13 \mu \mathrm{g} / \mathrm{mL}$ for Acinetobacter spp. isolate 3, whereas it was $6.25 \mu \mathrm{g} / \mathrm{mL}$ for both the Acinetobacter spp. isolates 1 and 3 (Figure 1). At these concentrations, bacterial inhibition growth was significantly inhibited $(p<0.001)$.

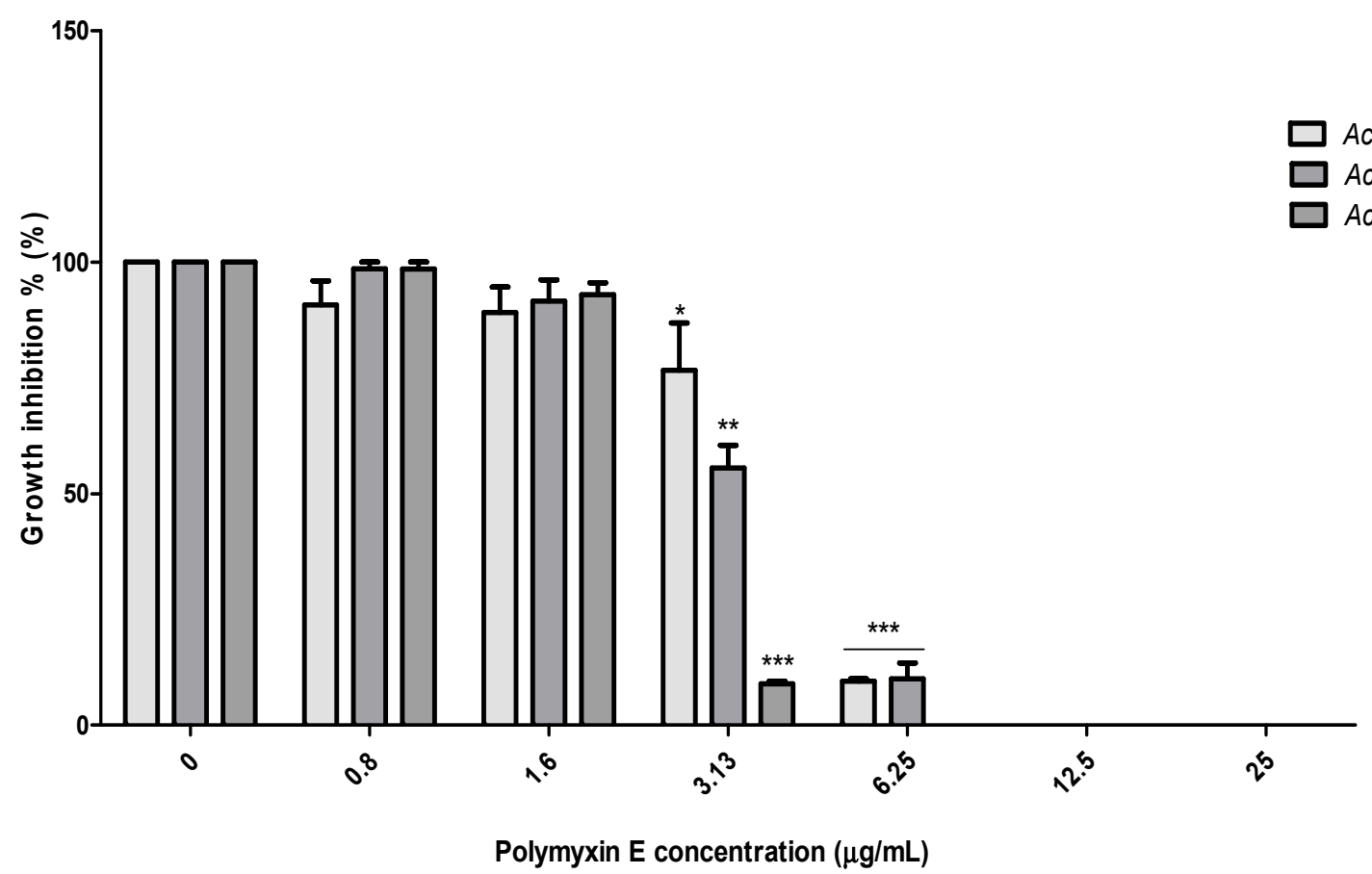

Figure 1. Antibacterial activity of polymyxin E against the selected Acinetobacter spp. isolates 1, 2, and 3. Data represented as mean MIC $\pm \mathrm{SEM}(\mu \mathrm{g} / \mathrm{mL})$ to three independent experiments. Asterisks refer to significance levels: ${ }^{*} p<0.05,{ }^{* *} p<0.01$, and ${ }^{* * *} p<0.001$.

No MIC values were determined for the CFS of B. subtilis KATMIRA1933 against the three isolated pathogens, even when the highest concentration (50\%) was used. Compared to the control (bacterial growth without treatment), only Acinetobacter spp. isolate 2 growth was inhibited $(p<0.05)$ at the concentration of $25 \%$. The Acinetobacter spp. isolates 2 and 3 were significantly inhibited $(p<0.01)$ at a concentration of $50 \%$, while the growth of Acinetobacter spp. isolate 1 was not influenced by the CFS of the tested Bacillus strains (Figure 2). Similarly, no MIC value for the CFS of B. amyloliquefaciens B-1895 was identified against the three isolates. However, significant growth inhibition $(p<0.01)$ of Acinetobacter spp. isolates 2 and 3 was noticed at a concentration of $12.5 \%$. At the highest concentration of B. amyloliquefaciens B-1895 CFS (50\%), the bacterial isolates growth was dramatically inhibited $(p<0.001)$ (Figure 3). 


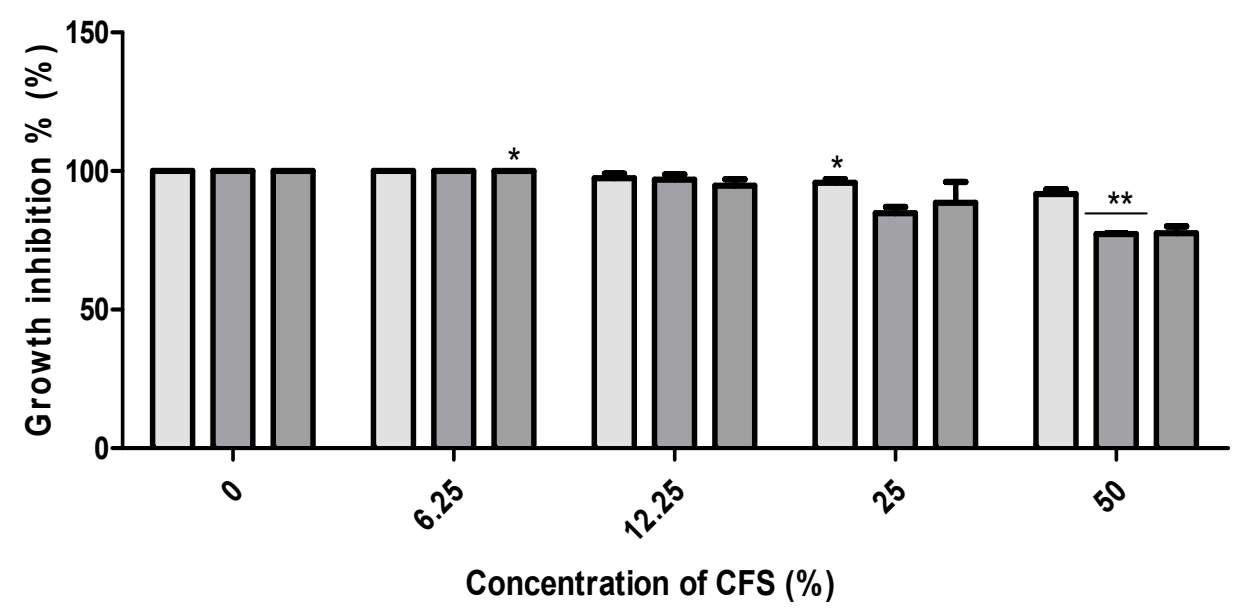

Acinetobacter spp. isolate 1 Acinetobacter spp. isolate 2 Acinetobacter spp. isolate 3

Figure 2. Antibacterial activity of B. subtilis KATMIRA1933 CFS against the selected Acinetobacter spp. isolates 1, 2, and 3. Data presented as mean MIC \pm SEM $(\mu \mathrm{g} / \mathrm{mL})$ to three independent experiments. Asterisks refer to significance levels: $* p<0.05$, and ${ }^{* *} p<0.01$.

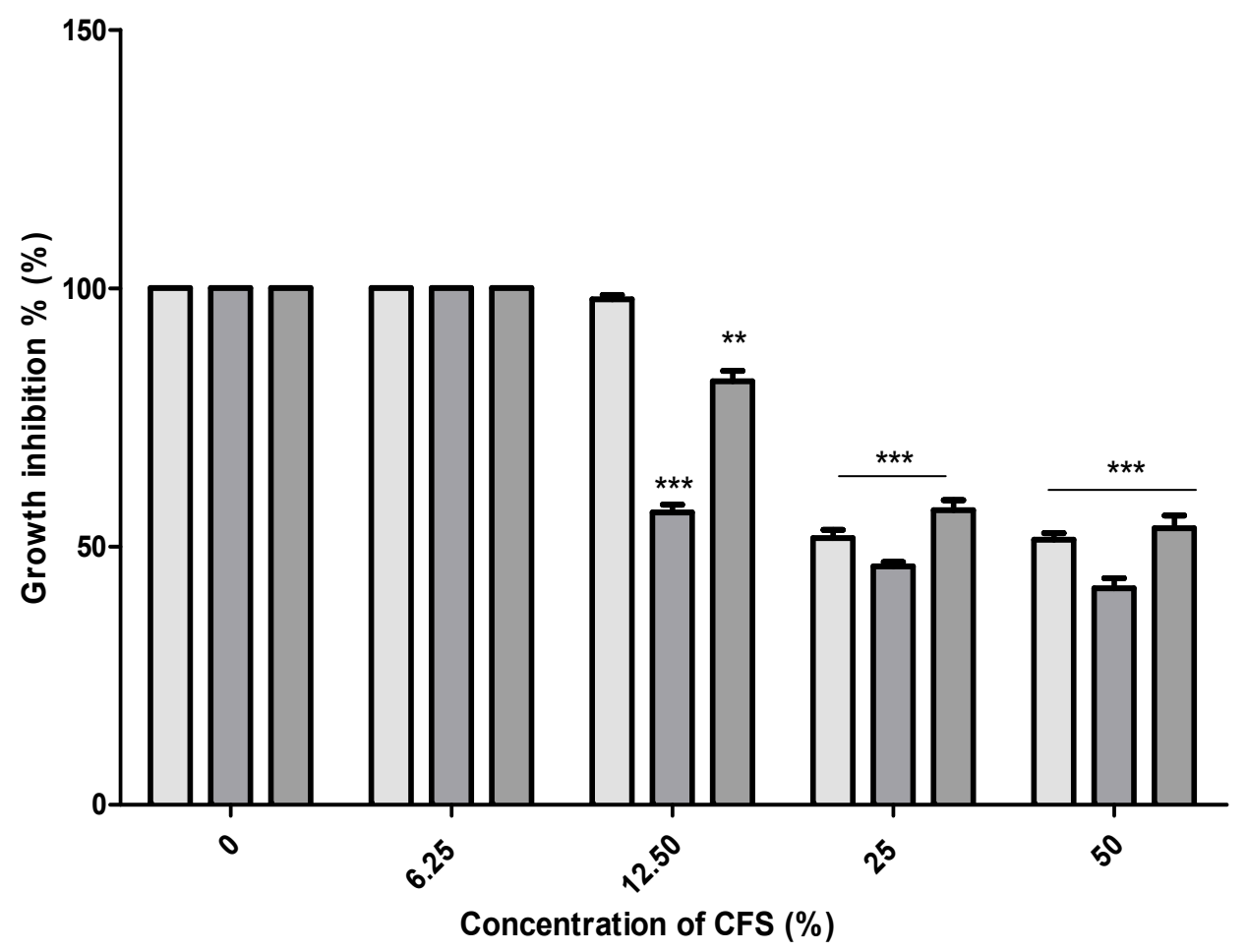

Figure 3. Antibacterial activity of B. amyloliquefaciens B-1895 CFS against the selected Acinetobacter spp. isolates 1, 2, and 3. Data presented as mean MIC $\pm \mathrm{SEM}(\mu \mathrm{g} / \mathrm{mL})$ to three independent experiments. Asterisks refer to significance levels: ** $p<0.01$, and ${ }^{* * *} p<0.001$.

\subsection{The Bacilli Strains Auto-Aggregated and Co-Aggregated with Isolated Pathogens}

Kinetic measurements of auto-aggregation and coaggregation of the probiotic bacilli strains with the three selected Acinetobacter spp. isolates were determined at 0,4 , and $24 \mathrm{~h}$ timepoints using an automated microplate reader at a wavelength of $630 \mathrm{~nm}$. After $4 \mathrm{~h}$ of incubation, the percentages of auto-aggregation of B. amyloliquefaciens B-1895 and B. subtilis KATMIRA1933 were $25.5 \%$ and $22.76 \%$, respectively. We noticed that, after $24 \mathrm{~h}$, the percentages of auto-aggregation increased as follows: B. amyloliquefaciens B-1895 and B. subtilis KATMIRA1933 were $95.7 \%$ and $82.4 \%$ (Table 3). In this study, the percentages of Acinetobacter spp. isolates 1, 2, and 3 auto-aggregation after $4 \mathrm{~h}$ of incubation were $24.5 \%$, 
$20.58 \%$, and $28.97 \%$, respectively, whereas, after $24 \mathrm{~h}$, they were lower, at $0.48 \%, 8.4 \%$, and $30.5 \%$, respectively (Table 3 ).

Table 3. Auto- and coaggregation of the tested bacilli strains at $4 \mathrm{~h}$ and $24 \mathrm{~h}$ of incubation.

\begin{tabular}{ccc}
\hline Bacterial Strains & $\begin{array}{c}\text { Auto- and Co-Aggregation \% } \\
\text { after } \mathbf{~} \mathbf{~ h}\end{array}$ & $\begin{array}{c}\text { Auto- and Co-Aggregation \% } \\
\text { after 24 h }\end{array}$ \\
\hline B. amyloliquefaciens B-1895 & $25.5 \%$ & $95.7 \%$ \\
B. subtilis KATMIRA1933 & $22.76 \%$ & $82.4 \%$ \\
Acinetobacter spp. isolates1, 2, and 3 & $(24.5 \%, 20.58 \%, 28.97 \%)$ & $(0.48 \%, 8.4 \%, 30.5 \%)$ \\
B. amyloliquefaciens B-1895 + Acinetobacter spp. isolate 1 & $23.98 \%$ & $50.57 \%$, \\
B. amyloliquefaciens B-1895 + Acinetobacter spp. isolate 2 & $29.39 \%$ & $55.64 \%$ \\
B. amyloliquefaciens B-1895 + Acinetobacter spp. isolate 3 & $17.15 \%$ & $50.67 \%$ \\
B. subtilis KATMIRA1933 + Acinetobacter spp. isolate 1 & $33.43 \%$ & $60.1 \%$, \\
B. subtilis KATMIRA1933 + Acinetobacter spp. isolate 2 & $31.89 \%$ & $53.16 \%$ \\
B. subtilis KATMIRA1933 + Acinetobacter spp. isolate 3 & $34 \%$ & $62.8 \%$ \\
\hline
\end{tabular}

Regarding bacterial coaggregation, after $4 \mathrm{~h}$, a high coaggregation percentage was observed when B. subtilis KATMIRA1933 was mixed with Acinetobacter spp. isolates 1, 2 , and 3 , at $33.43 \%, 31.89 \%$, and $34 \%$, respectively. When B. amyloliquefaciens B-1895 was mixed with Acinetobacter spp. isolates 1, 2, and 3, the coaggregation percentages were $23.98 \%, 29.39 \%$, and $17.15 \%$, respectively. After $24 \mathrm{~h}$ incubation, the percentages of coaggregation were higher compared to $4 \mathrm{~h}$. B. subtilis KATMIRA1933 was co-aggregated with Acinetobacter spp. isolates 1, 2, and 3 at $60.1 \%, 53.16 \%$, and $62.8 \%$, respectively, and the coaggregation of B. amyloliquefaciens B-1895 with Acinetobacter spp. isolates 1, 2, and 3 was $50.57 \%, 55.64 \%$, and $50.67 \%$, respectively. The highest scores of coaggregation that appeared after $24 \mathrm{~h}$ were stained and photographed using light microscopy, as shown in Figure 4.

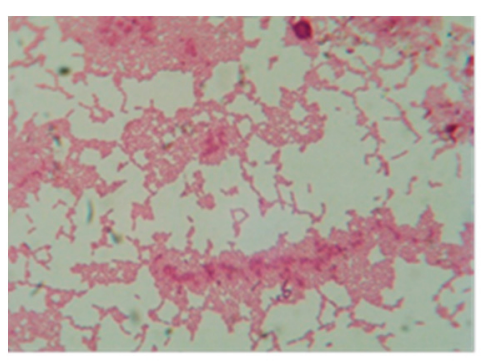

A

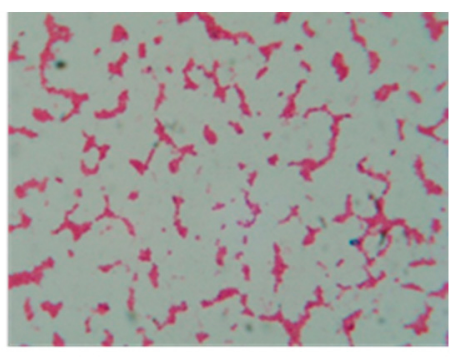

B

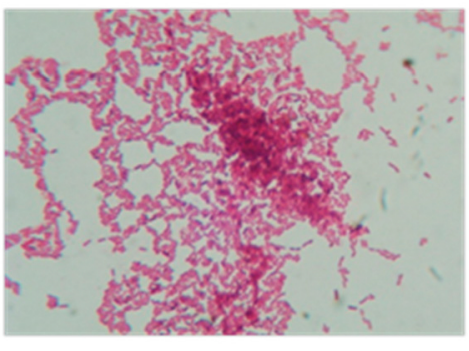

c

Figure 4. Auto and coaggregation of the tested bacilli strains with the selected Acinetobacter spp. isolates. (A) Autoaggregation of B. amyloliquefaciens B-1895; (B) autoaggregation of Acinetobacter spp. isolates (some auto-aggregation); (C) coaggregation of B. amyloliquefaciens B-1895 with Acinetobacter spp. isolates (coaggregation). Bacterial auto- and coaggregations were captured under a biological microscope using oil immersion at $1000 \times$ magnification; the scale bar is $10 \mu \mathrm{L}$. 


\subsection{Minimum Biofilm Inhibitory Concentrations (MBIC)}

MBICs were determined using the broth-microtiter dilution method. Regarding polymyxin E, there was biofilm formation inhibition at 1.65 and $3.13 \mu \mathrm{g} / \mathrm{mL}$ as compared to the positive control (Figure 5). The MBIC of polymyxin E was $3.13 \mu \mathrm{g} / \mathrm{mL}$ for the selected Acinetobacter spp. isolate 3 with $95-100 \%$ biofilm inhibition, while the MBIC value for Acinetobacter spp. isolates 1 and 2 was $6.25 \mu \mathrm{g} / \mathrm{mL}$ at which a significant reduction $(p<0.001)$ in biofilm formation was reported, with $85 \%$ and $83.4 \%$ inhibition for Acinetobacter spp. isolates 1 and 2, respectively (Figure 5).

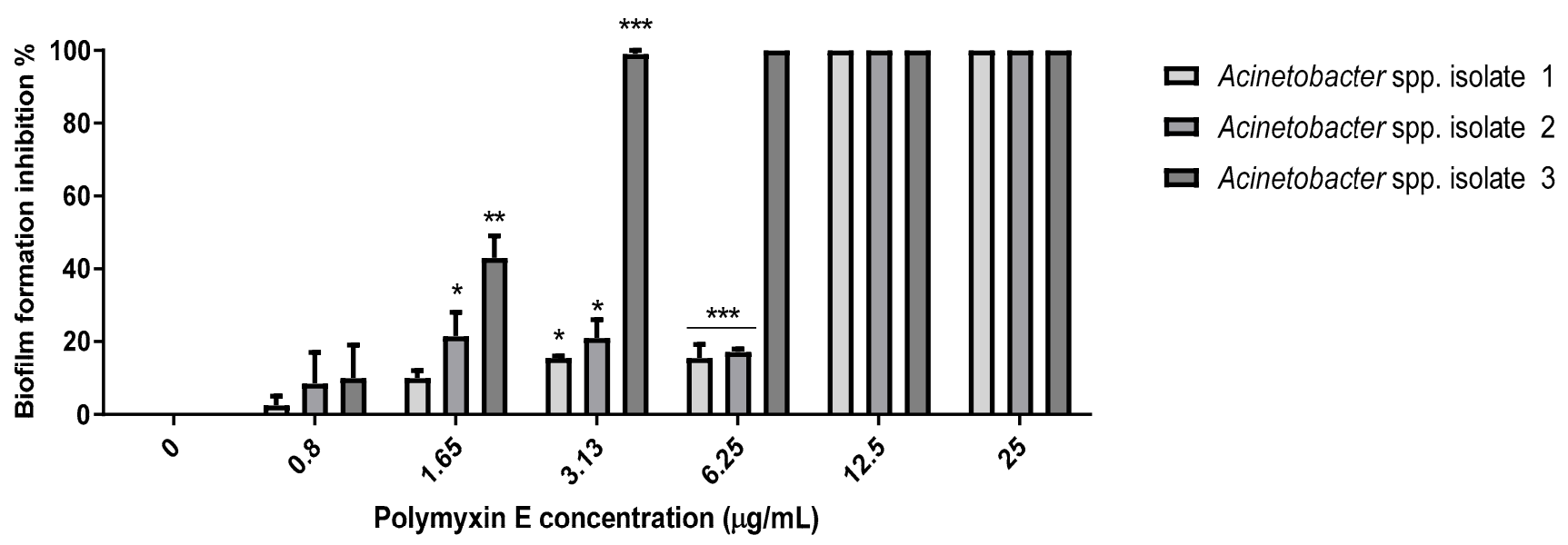

Figure 5. Anti-biofilm activity of polymyxin E against the selected Acinetobacter spp. isolates 1, 2, and 3. Data presented as mean MIC \pm SEM $(\mu \mathrm{g} / \mathrm{mL})$ to three independent experiments. Asterisks refer to significance levels: ${ }^{*} p<0.05,{ }^{* *} p<0.01$, and ${ }^{* * *} p<0.001$.

In our study, no MBIC value for the B. subtilis KATMIRA1933 CFS was determined against the selected isolates, even when the highest concentration of $50 \%$ was used. A concentration of $50 \%$ CFS of B. subtilis KATMIRA1933 prevented $7.3 \%, 23.3 \%$, and $22.5 \%$ of the biofilm formation by Acinetobacter spp. isolates 1, 2, and 3, respectively, with a significant difference $(p<0.01)$ (Figure 6). Similarly, no MBIC was determined when $B$. amyloliquefaciens B-1895 CFS was used. However, a slight reduction (5-10\%) was reported in biofilm formation by Acinetobacter spp. isolate 1 at $12.5 \%$ and $25 \%$ (Figure 7). At 50\%, a significant $(p<0.01)$ reduction $(48.7 \%)$ was reported in biofilm formed by the Acinetobacter spp. isolate 1 . In the same regard, 50\% CFS of B. amyloliquefaciens B-1895 significantly $(p<0.05)$ reduced biofilm formation by $28.4 \%$ and $33.6 \%$ for Acinetobacter spp. isolates 2 and 3 , respectively.

\subsection{The Polymyxin E Synergizes with Bacilli CFS}

Initially, a modified Kirby-Bauer method was used to determine the antibiotic susceptibility of the selected Acinetobacter spp. isolates to polymyxin E alone and combined with the CFS of tested probiotic strains.

We found a significant increase in the inhibition of the selected Acinetobacter spp.strains growth when the CFS of the two bacilli strains were combined with polymyxin E, compared to using the antibiotic alone (Figure 8). Polymyxin E alone produced a zone of inhibition around the Acinetobacter spp. isolates 1, 2, and 3 (11 mm for each), while Acinetobacter spp. isolate 3 had a $10 \mathrm{~mm}$ zone of inhibition around the same antibiotic disc (Figure 8). When the CFS of B. subtilis KATMIRA1933 was combined with polymyxin E, the diameters of the zones of inhibition for Acinetobacter spp. isolates 1, 2, and 3 were 12, 14, and $16 \mathrm{~mm}$, respectively. In the same regard, the zone inhibition was significantly increased (13 mm; $p<0.01$ ) when the polymyxin E disc was combined with the CFS of B. amyloliquefaciens B-1895. 


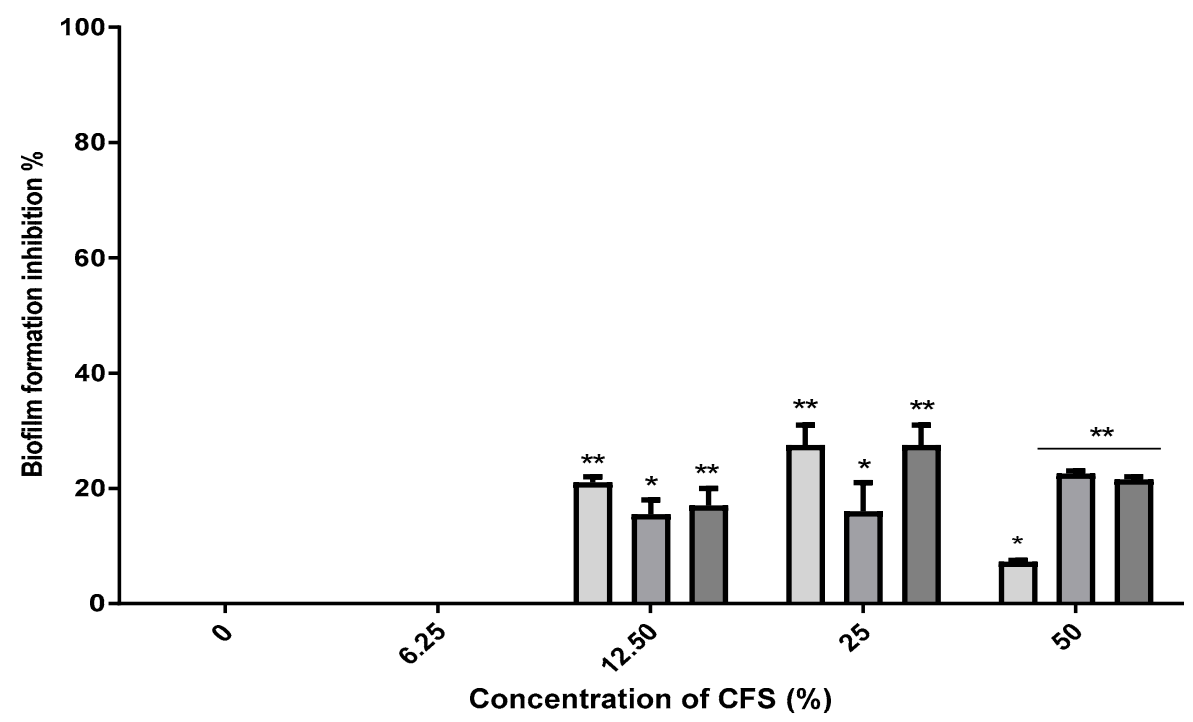

- Acinetobacterspp. isolate 1

ש Acinetobacter spp. isolate 2

D Acinetobacterspp. isolate 3

Figure 6. Anti-biofilm activity of B. subtilis KATMIRA1933 CFS against the selected Acinetobacter spp. isolates 1, 2, and 3. Data presented as mean MIC \pm SEM (\%) to three independent experiments. Asterisks refer to significance levels: ${ }^{*} p<0.05$, and ${ }^{* *} p<0.01$.

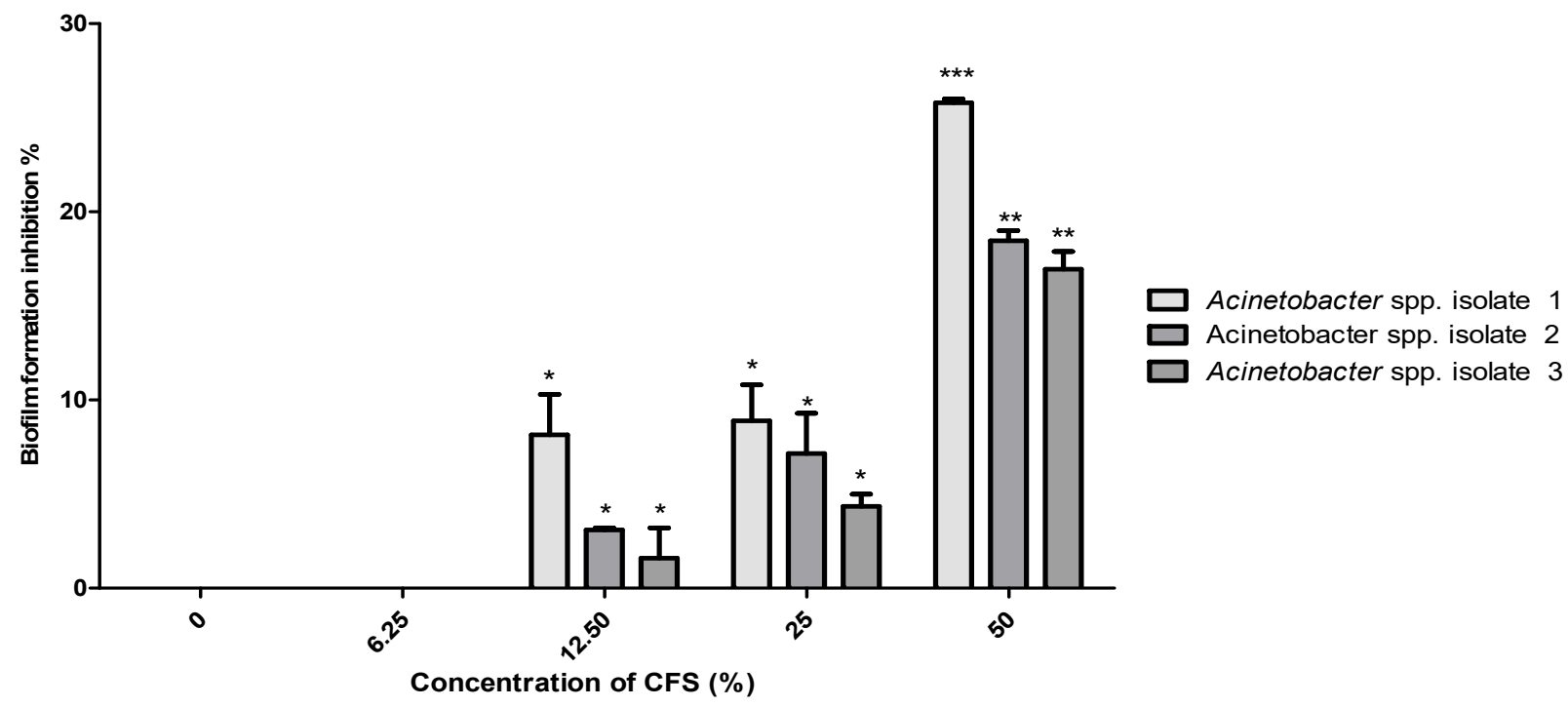

Figure 7. Anti-biofilm activity of B. amyloliquefaciens B-1895 CFS against the selected Acinetobacter spp. isolates 1, 2, and 3.. Data presented as mean MIC \pm SEM (\%) to three independent experiments. Asterisks refer to significance levels: ${ }^{*} p<0.05$, ${ }^{* *} p<0.01$ and ${ }^{* * *} p<0.001$. 


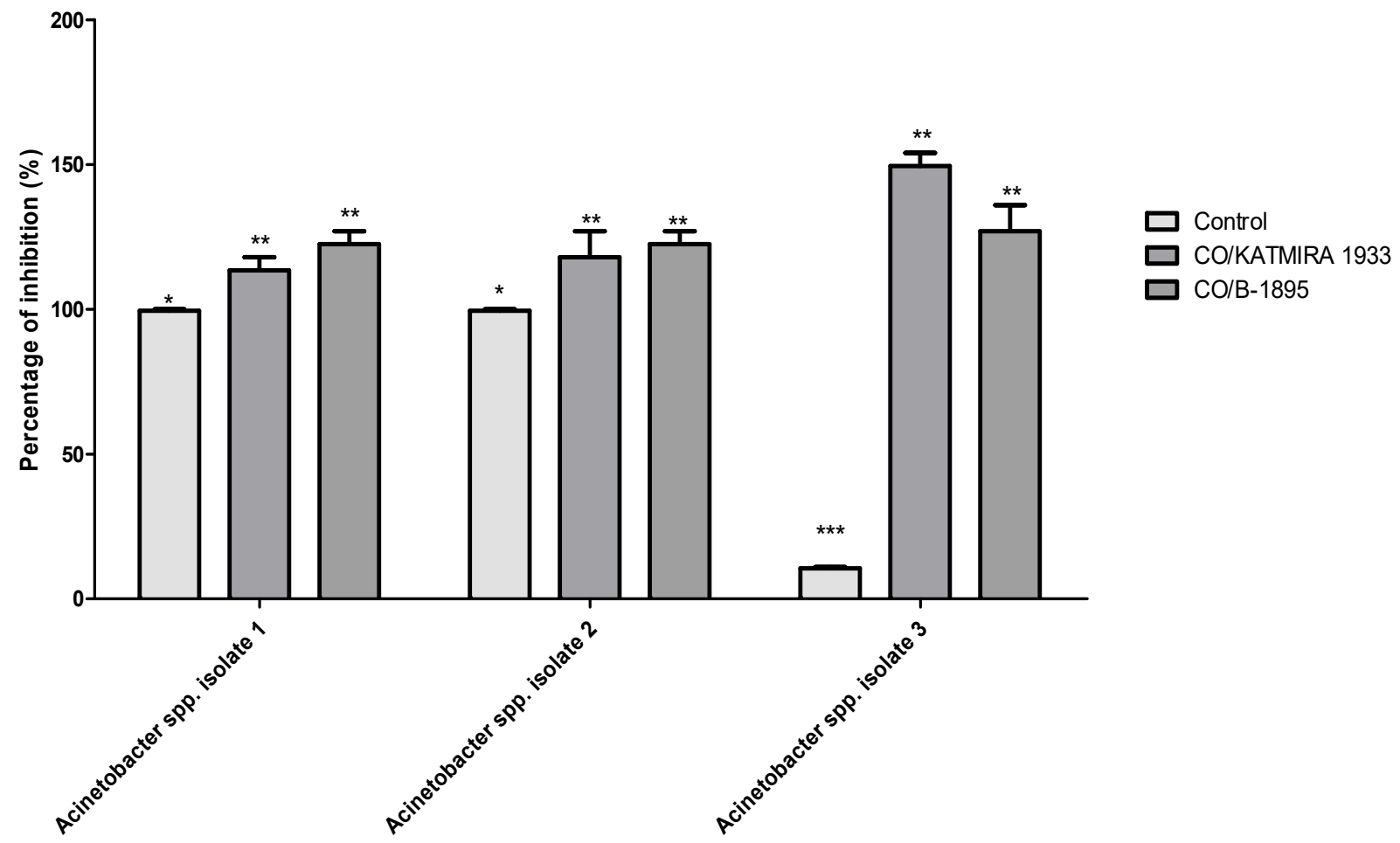

Figure 8. Zone of the selected Acinetobacter spp. isolates growth inhibition when polymyxin E was used alone and in combination with the CFS of the tested probiotic strains using disc diffusion method. Data presented as mean $\pm \mathrm{SEM}$ to three independent experiments. Asterisks refer to significance levels: ${ }^{*} p<0.05,{ }^{* *} p<0.01$, and ${ }^{* * *} p<0.001$.

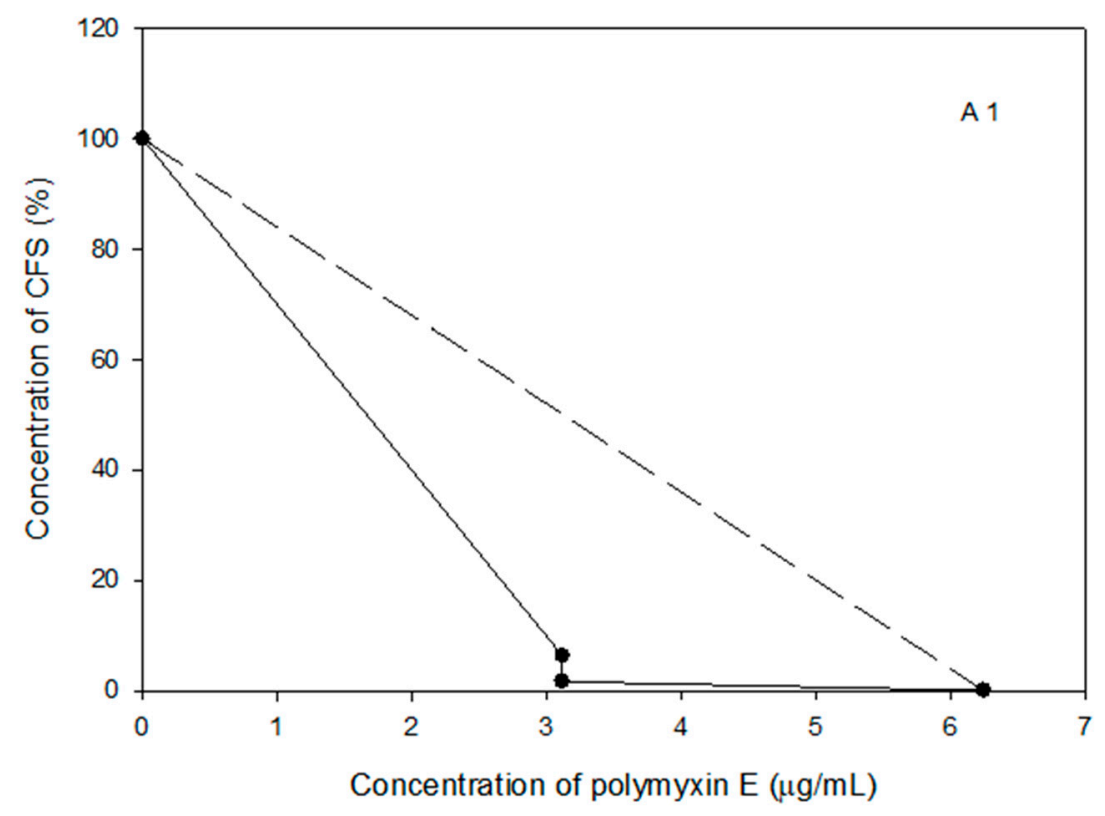

Figure 9. Cont. 

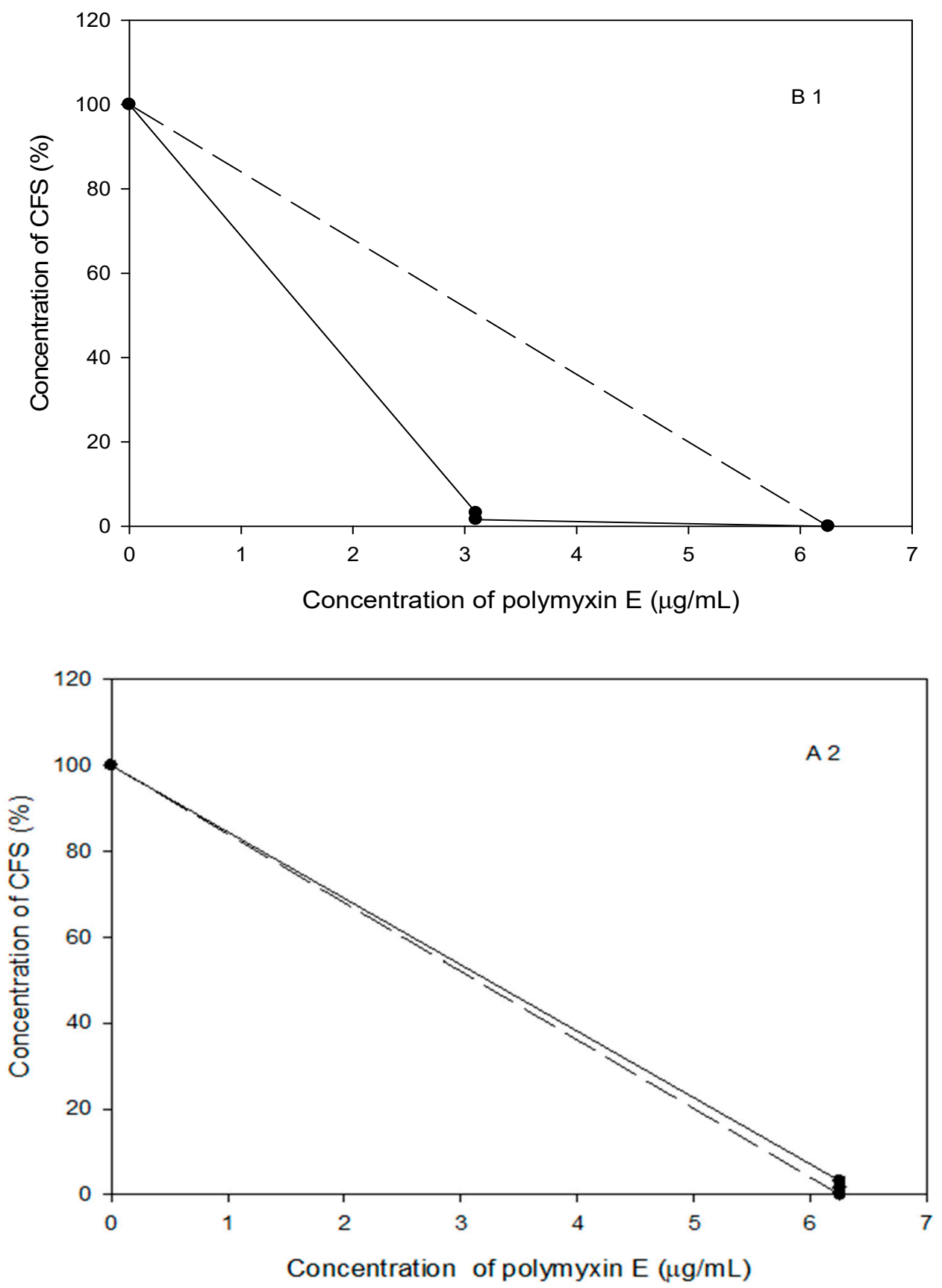

Figure 9. Cont. 

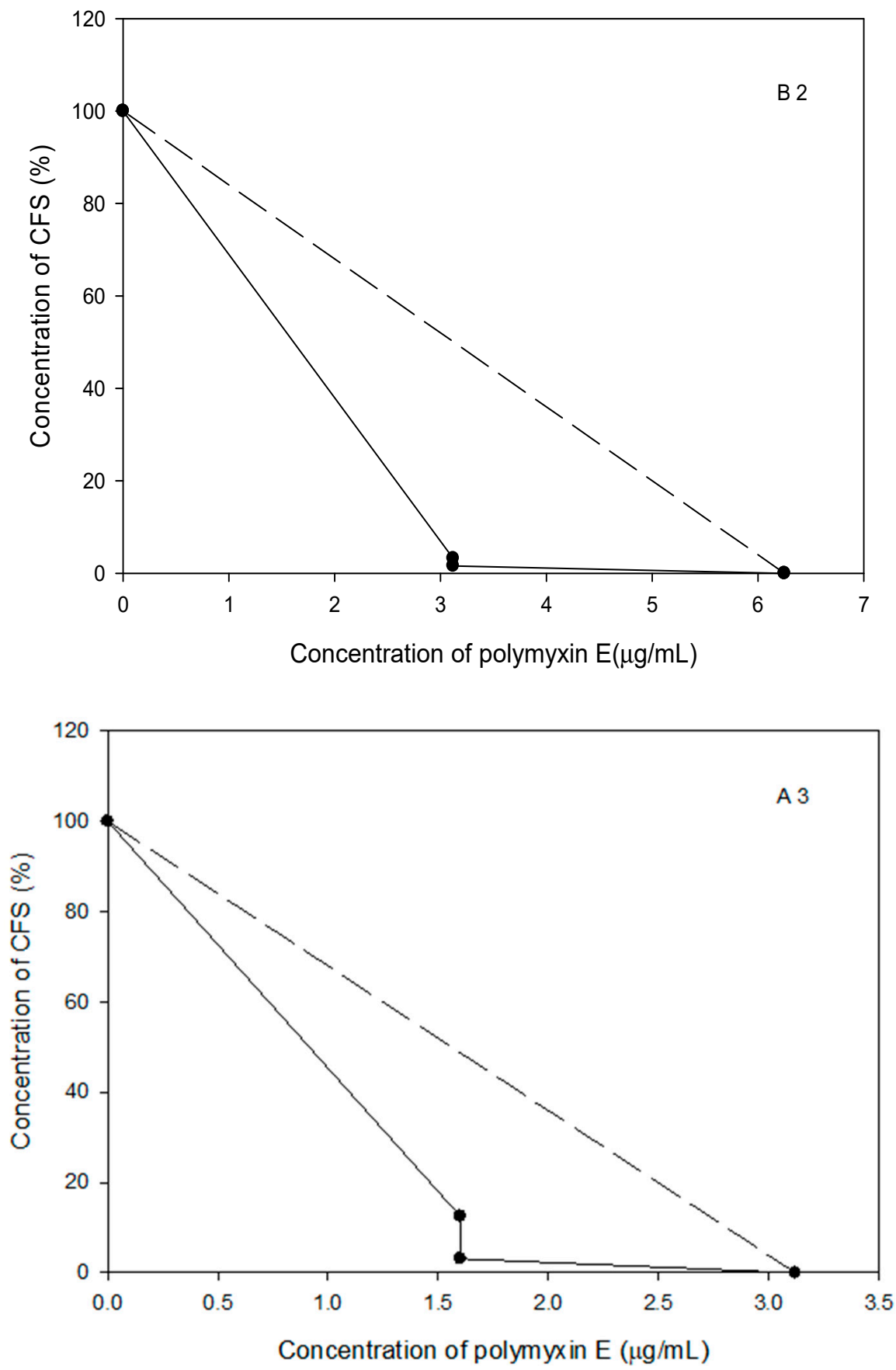

Figure 9. Cont. 


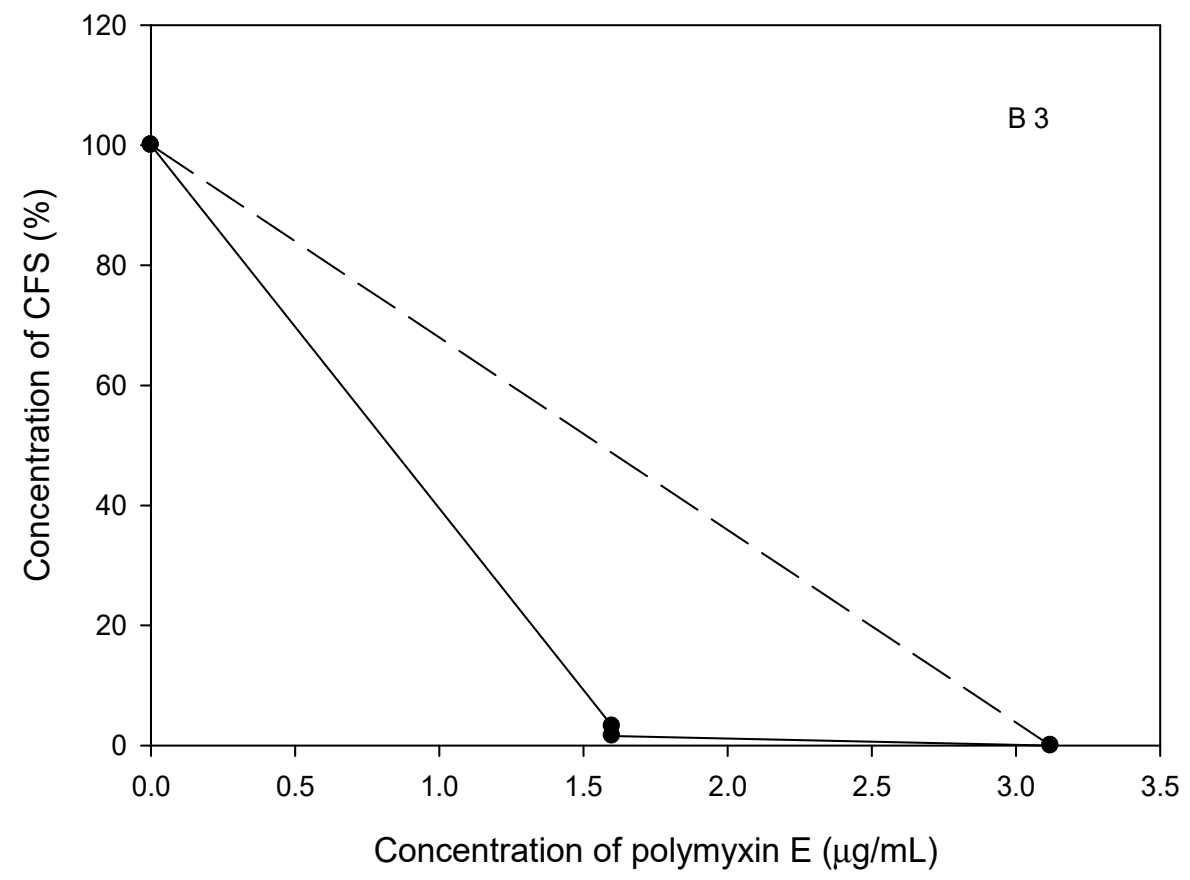

Figure 9. (A,B) (1-3). Isobolograms of polymyxin $\mathrm{E}$ in combination with CFS of probiotic strains against planktonic cells of the selected Acinetobacter spp. (A) B. amyloliquefaciens B-1895, (B) B. subtilis KATMIRA1933), (1-3) referred to the Acinetobacter spp. isolate numbers. The dashed lines connect the two MIC values (closed circles), while the solid lines connect the sub-MIC vlues (closed circles below the dashed lines).

Regarding the Acinetobacter spp. isolate 2, synergistic activity was identified when polymyxin E was combined with the CFS of B. subtilis KATMIRA1933 but not with the CFS of B. amyloliquefaciens B-1895. The MIC of polymyxin E was 2-fold lower, and the CFS B. subtilis KATMIRA1933 was more than 17 -fold lower than their individual MIC values $(3.13 \mu \mathrm{g} / \mathrm{mL}$ of polymyxin $\mathrm{E}$ in combination instead of $6.25 \mu \mathrm{g} / \mathrm{mL}$ alone and $1.6-3.13 \%$ of CFS in combination compared to more than 50\% when used alone) (Figure 9(B2)). An additive effect was reported when polymyxin $\mathrm{E}$ was combined with the CFS of $B$. amyloliquefaciens B-1895. The MIC of polymyxin E was not changed $(6.25 \mu \mathrm{g} / \mathrm{mL})$, while the MIC of the bacilli CFS was more than 16-fold lower (1.65-6.25\% of CFS in combination compared to more than $50 \%$ when used alone) (Figure 9(A2)). The total $\sum$ FIC showed synergism between polymyxin E and the CFS of B. subtilis KATMIRA1933 but not with the CFS of B. amyloliquefaciens B-1895 against the Acinetobacter spp. isolate 2. The $\sum$ FIC was 0.516 and 1.02 when polymyxin E was combined with B. subtilis KATMIRA1933 and B. amyloliquefaciens B-1895, respectively, against biofilm cells.

Synergistic activity was also noticed when polymyxin E was combined with the CFS of the probiotic strains against the Acinetobacter spp. isolate 3. The MIC of polymyxin E was 4-fold lower and the CFS of B. subtilis KATMIRA1933 was more than 8-16 fold lower $(1.63 \mu \mathrm{g} / \mathrm{mL}$ of polymyxin E in combination instead of $6.25 \mu \mathrm{g} / \mathrm{mL}$ alone and $1.6-3.13 \%$ of CFS in combination compared to more than $50 \%$ when it was used alone) (Figure 9(B3)). Similarly, the MIC of polymyxin E was 4-fold lower, and the CFS of B. amyloliquefaciens B-1895 was more than $8-16$ fold lower when combined $(1.63 \mu \mathrm{g} / \mathrm{mL}$ of polymyxin $\mathrm{E}$ in combination instead of $6.25 \mu \mathrm{g} / \mathrm{mL}$ alone and $3.13-12.5 \%$ of CFS in combination compared to more than $50 \%$ when used alone) (Figure 9(A3)). The total $\sum$ FIC showed synergy between polymyxin E and the CFS of the probiotic strains against the Acinetobacter spp. isolate 3 . The $\sum F I C$ was 0.381 and 0.272 when polymyxin $\mathrm{E}$ was combined with $B$. subtilis KATMIRA1933 and B. amyloliquefaciens B-1895, respectively, against biofilm cells. 


\section{Discussion}

Recently, there has been an increase in the number of multidrug-resistant Acinetobacter spp. isolates (about 90\%) from burns and other wounds [14]. The high prevalence of multidrug-resistant Acinetobacter spp. infections is associated with several factors, such as the (a) acquisition of nosocomial pathogens during long-term hospitalization, (b) delayed administration of antimicrobial agents, and (c) patients having immunosuppressive factors [15]. On MacConkey agar, the bacterial colonies appeared as described by ALDahlaki [16]. Importantly, the ability to grow at $44{ }^{\circ} \mathrm{C}$ is a feature that distinguishes Acinetobacter spp. isolates from the rest of this genus [6]. The VITEK 2 system was used to confirm bacterial identification, and additionally, to evaluate the antibiotic susceptibility of the selected Acinetobacter spp. isolates. The VITEK 2 identification system is unable to discriminate between $A$. baumannii and $A$. nosocomialis, which requires an analysis of the $r p o B$ gene. In this study, the isolated pathogens were indicated as "selected Acinetobacter spp. isolates". The future mechanistic study of the newly isolated pathogens will include their taxonomic identification using the appropriate approach.

Our results demonstrated that the bacterial isolates were tolerant to the imipenem and meropenem $\beta$-lactam antibiotic classes (Table 1). AL-Dahlaki [16], found that $95 \%$ of the tested Acinetobacter spp. isolates were resistance to carbapenems, imipenem, and meropenem. Our findings showed that the tested pathogens were resistant to ampicillin and piperacillin/tazobactam (100\%). These results were in agreement with a study of AL-Dahlaki [16], who found that $100 \%$ of Acinetobacter spp. isolates showed resistance to piperacillin/tazobactam. Furthermore, Raut et al. [17] and Pal et al. [18] found that Acinetobacter spp. isolates were mostly resistant to piperacillin/tazobactam and survived in the presence of ampicillin.

In regard to cephalosporins, our data were in agreement with Pal et al. [18], who found that $100 \%$ of Acinetobacter spp. isolates were resistant to cephalosporins.

$\beta$-lactamase production by Acinetobacter spp. isolates plays an important role in their tolerance to $\beta$-lactam antibiotics. This enzyme breaks down the amide bond of the $\beta$-lactam ring, causing inactivation of these types of antibiotics. Moreover, modifying penicillinbinding proteins in bacterial cells will decrease the permeability of the outer membrane porins and excretion of $\beta$-lactam antibiotic from the cell by the efflux pump [6].

Our findings showed that the three selected isolates were susceptible to polymyxin E. Only Acinetobacter spp. isolate 1 was resistant to tigecycline and minocycline. These findings were similar to those of Rahimi et al. [19], who reported that the isolated Acinetobacter spp. were sensitive to polymyxin E. In addition, $94 \%$ and $73 \%$ of isolates were sensitive to tigecycline and minocycline. The study of Raut et al. [17] showed that $A$. baumannii isolates were $100 \%$ susceptible to polymyxin E and tigecycline.

Polymyxin E, a bactericidal substance, is widely used to control MDR isolates by disrupting bacterial cell membranes [17]. It has a positively charged cationic region that binds to the hydrophilic portion of bacterial lipopolysaccharides leading to the eventual loss of cellular membrane integrity [20]. Tetracyclines and glycylcyclines inhibit protein synthesis of bacterial cells by preventing aminoacyl-tRNA binding to the ribosome [21]. In the same regard, $A$. baumannii possesses Tet $A$ and TetB genes, which control the efflux of antibiotics outside the bacterial cell [22].

In regard to trimethoprim/sulfamethoxazole, we noticed that only Acinetobacter spp. isolate 3 was inhibited (Table 1). The presence of dihydrofolate reductases (DHFR and FolA) in Acinetobacter spp. isolates plays an important role in bacterial resistance to trimethoprim [23]. Fluoroquinolone resistance was reported in the three selected isolates of Acinetobacter spp. Fluoroquinolones are broad-spectrum antibiotics; however, an increase in bacterial resistance to fluoroquinolones has been reported over the past several years [17]. A major mechanism for quinolone resistance was identified in the mutated genes gyrA and $\operatorname{parC}$, which led to phenotypic changes in DNA gyrase and topoisomerase IV, reducing antibiotic affinity [24]. 
Our findings show that Acinetobacter spp. isolate 1 and Acinetobacter spp. isolate 2 were resistant to amikacin, gentamicin, and tobramycin (Table 1). These data are in agreement with the work of AL-Dahlaki [16], who reported that most A. baumannii isolates were resistant to amikacin, gentamicin, and tobramycin.

Aminoglycoside resistance could be related to aminoglycoside-modifying enzymes (AMEs) produced by Acinetobacter spp. These enzymes change the corresponding functional groups of aminoglycosides and disrupt the binding capacity of these antibiotics at their ribosomal target sites [25]. Moreover, aminoglycosides resistance is associated with 16S rRNA methylase genes, which alter the bacterial-binding site of aminoglycosides within the $30 S$ ribosomal subunit. Methylases stimulate high-level resistance to aminoglycosides, including amikacin, gentamicin, and tobramycin [25].

In regard to the susceptibility of the probiotic strains to antibiotics, six antibiotics were evaluated using the disc diffusion method (Kirby-Bauer). Our findings showed that bacilli strains were susceptible to the majority of the selected antibiotics (Table 2), while they were tolerant to polymyxin E. In addition, B. amyloliquefaciens B-1895 showed tolerance to amikacin. Polymyxin E is a non-ribosomal peptide produced by Bacillus polymyxa, a soil bacterium, as a secondary metabolite with bactericidal activity against Gram-negative bacteria [7].

According to the Clinical and Laboratory Standards Institute (CLSI) [26] guidelines, the selected Acinetobacter spp. isolates were classified into two major classes; MDR (resistant to $\geq 3$ of all antibiotic categories) or XDR (resistant to all antibiotics except two or fewer belong to the same category). Acinetobacter spp. isolate 3 was MDR, while both Acinetobacter spp. 1 and 2 were XDR isolates. A complete picture of antibiotic resistance for the tested isolates was created according to the criteria outlined by Magiorakos et al. [27]. Our results agree with the data of Rahimi et al. [19], who found that $76 \%$ of Acinetobacter spp. isolates exhibited an XDR phenotype. Recently, several studies highlighted the obstacle of increasing resistance to antibiotics and the global spread of multidrug-resistant bacteria [28]. An increasing trend in the emergence of XDR strains was also reported over the last decade in Iran [29]. The development of antibiotic resistance in Acinetobacter spp. strains is related to the ability to form biofilms. In the current study, we found that the three isolated Acinetobacter spp. were capable of forming strong biofilms. The ability of Acinetobacter spp. to form biofilms could explain the outstanding resistance to antibiotics, long-time survival in harsh environments, and tolerance for disinfectants and/or desiccation on abiotic surfaces [30]. Several factors are involved in biofilm formation and antibiotic resistance of Acinetobacter spp., including biofilm-associated proteins (Bap), efflux systems (AdeABC, AdeFGH, and AdeIJK), quorum sensing systems, and motility by pili [31].

The broth micro-dilution method was used to determine the MIC of polymyxin E and the tested probiotic CFS against Acinetobacter spp. isolates 1, 2, and 3. The data showed that Acinetobacter spp. isolate 3 was more sensitive to polymyxin E compared to Acinetobacter spp. isolates 1 and 2, the MICs were 3.13-6.25 $\mu \mathrm{g} / \mathrm{mL}$ (Figure 1). Our results were similar to a study by Sato et al. [32], who reported that the MIC of polymyxin E against $A$. baumannii was $4 \mu \mathrm{g} / \mathrm{mL}$. However, a study by Lin et al. [33] found a lower MIC value for polymyxin $\mathrm{E}(1 \mu \mathrm{g} / \mathrm{mL})$ against $A$. baumannii. The variation in the MIC values might be related to the source and manufacture of the antibiotic, in addition to differences in experimental designs and conditions.

Regarding the MIC for the CFS of B. subtilis KATMIRA 1933, only the Acinetobacter spp. isolate 2 showed growth inhibition $(p<0.05)$ at a concentration of $25 \%$. The Acinetobacter spp. isolates 2 and 3 were inhibited significantly $(p<0.01)$ at a concentration of $50 \%$ (Figure 2). Significant growth inhibition $(p<0.01)$ of Acinetobacter spp. isolates 2 and 3 was found at $12.5 \%$, while at the highest concentration of B. amyloliquefaciens B-1895 CFS (50\%), the bacterial isolates were dramatically inhibited ( $p<0.001)$ (Figure 3). Efremenkova et al. [34] proposed that Bacillus strain 534 can produce active substances with different molecular sizes that target the cellular envelope of the pathogenic microorganisms. Several studies have been performed to evaluate the antimicrobial activity of the 
metabolites extracted from various species of probiotics against $A$. baumannii. Shin and Eom [3] referred to the antimicrobial activity of $C$. butyricum CFS against $A$. baumannii strains. In the presence of $50 \%$ of C. butyricum CFS, $98.51 \%$ of $A$. baumannii growth was inhibited. A study by Soltan et al. [35] showed that lactobacilli prevented the growth of A. baumannii and P. aeruginosa. During the stationary phase of growth, lactobacilli and bacilli strains secrete weak organic acids, bacteriocins, and biosurfactants. Bacteriocins are antimicrobial peptides ribosomally produced by virtually all microorganisms [36]. These peptides interact with the bacterial cell surface and cell membrane, leading to cell permeabilization and pore formation, and eventually, depletion of intracellular ATP (because of the collapse of the proton motive force) and cellular death (after leakage of intracellular substrates-please, see the review of Kumariya et al. [37]).

For coaggregation, the results illustrated that the percentages of coaggregation after $24 \mathrm{~h}$ incubation were higher compared to $4 \mathrm{~h}$. Similarly, Algburi et al. [38] reported high levels of coaggregation of pathogenic P. mirabilis, isolated from urinary tract infections, with B. amyloliquefaciens B-1895 and B. subtilis KATMIRA1933 after $24 \mathrm{~h}$ incubation. Coaggregation of probiotic strains with pathogenic bacteria is indicative of competition between the two bacterial species on the attached surfaces, which may play an important role in inhibiting biofilm formation [39].

The minimum biofilm inhibitory concentration is defined as the concentration of an antimicrobial that inhibits either 50\% (MBIC-50) or 90\% (MBIC-90) of biofilm formation compared to the untreated control group [40]. Our findings were close to the study of Lin et al. [33], who found that MBIC of polymyxin E against Acinetobacter spp. isolates was $8.192 \mu \mathrm{g} / \mathrm{mL}$.

In our study, 7.3-23.3\% of the biofilm was prevented when 50\% CFS of B. subtilis KATMIRA1933 was used. Similarly, no MBIC was determined when B. amyloliquefaciens B1895 CFS was used, while using 50\% CFS of B. amyloliquefaciens B-1895 prevented $28.4-48.7 \%$ of the biofilm formed by the selected Acinetobacter spp. isolates (Figure 7).

The antibacterial and anti-biofilm activity of our tested bacilli CFS was reported by Algburi et al. [38] against biofilm formation by Proteus mirabilis isolated from urine samples of sheep and patients have urinary tract infections. The authors reported that $25 \%$ and $50 \%$ CFS of B. subtilis KATMIRA1933 prevented $3 \%$ and $15.6 \%$ of planktonic cells and effectively inhibited 75-84\%, respectively, of biofilm formation by $P$. mirabilis of human sources. In regard to B. amyloliquefaciens B-1895 CFS, planktonic growth of P. mirabilis (human isolate) decreased by $2.9 \%$ and $11.3 \%$ when the CFS of bacilli at $25 \%$ and $50 \%$ were used, correspondingly. In addition, $72 \%$ and $81 \%$ of $P$. mirabilis biofilm (human isolate) were inhibited when $25 \%$ and $50 \%$ of the CFS were applied, respectively. Similarly, using $25 \%$ and $50 \%$ of the CFS of B. amyloliquefaciens B-1895 caused $38 \%$ and $59 \%$ biofilm prevention and reduced the density of planktonic cells of $P$. mirabilis (isolated from sheep) by $65.3 \%$ and $69.1 \%$, respectively. In the presence of $25 \%$ and $50 \%$ CFS of B. subtilis KATMIRA1933, $51 \%$ and $57 \%$, respectively, and the accumulated biofilm $P$. mirabilis isolated from sheep was decreased [38]. The planktonic cells growth and biofilm formation were measured at $\mathrm{OD}_{600}$.

The CFS obtained from probiotic species contains various biologically active compounds, including exopolysaccharides, proteins, biosurfactants, and digestive enzymes. These substances are associated with the inhibition or destruction of the preformed biofilm [39].

Our data showed a significant increase in the selected Acinetobacter spp. strains growth inhibition when the CFS of bacilli strains was combined with polymyxin E, compared to the use of the antibiotic alone (Figure 8). Other studies have also evaluated antimicrobial combinations of the CFS of probiotic strains with antibiotic discs. For example, Isayenko et al. [10] found an increase in the diameter of the zones of inhibition for A. baumannii when antibiotics were combined with the metabolite complexes of Lactobacillus rhamnosus (re-classified as Lacticaseibacillus rhamnosus) and Saccharomyces boulardii using the modified disk-diffusion method. Using the same method, in a recent study, Algburi et al. [41] reported on the 
complementary activity of cefotaxime combined with the CFS of B. subtilis KATMIRA1933 and B. amyloliquefaciens B-1895 against methicillin-resistant Staphylococcus aureus.

In addition to the disk-diffusion method, a checkerboard assay was also used to evaluate the antimicrobial combinations. Our results showed that the antimicrobial activity of polymyxin $\mathrm{E}$ was enhanced when combined with the CFS of tested bacilli against planktonic and biofilm associated cells of the selected Acinetobacter spp. isolates. Various studies have been conducted to investigate the nature of antimicrobial reactions. Mathur et al. [42] found synergistic anti-biofilm activity for nisin combined with polymyxins against $P$. aeruginosa: No inhibition in P. aeruginosa biofilm was noticed when nisin $(1 / 3 \times \mathrm{MIC})$ and polymyxin $\mathrm{E}(1 / 5 \times \mathrm{MIC})$ were used alone, while significant biofilm prevention was found (more than $15 \%$ ) when polymyxin E was combined with nisin at the same concentrations. The synergy of polymyxins with other antimicrobials could be an attractive approach for controlling MDR pathogens after ensuring the safety of these combinations on human health.

Probiotic strains produce antimicrobial substances such as organic acids, bacteriocins, hydrogen peroxide, and biosurfactants [43]. The synergistic interactions of biologically active substances produced by probiotics together with antibiotics can (i) increase their antimicrobial activity when used in industrial and medical applications, (ii) reduce the concentrations of both antimicrobials when they are used alone, (iii) and prevent the development of bacterial resistance. These advantages are urgently required to extend the usage of existing antibiotics [44]. Previously, we reported on the synergy between B. subtilis KATMIRA1933-produced subtilosin A and antibiotics (clindamycin and metronidazole) against planktonic cells [45] and biofilms [46] of Gram-variable human pathogen Gardnerella vaginalis. Based on the draft genome sequence of Bacillus amyloliquefaciens B-1895 [47], the microorganism bears several genes potentially coding for various cyclic peptide antibiotics, some of which may also act synergistically with selected antibiotics and other stressors. Taking probiotics concurrently with antibiotics may reduce the threatening effect of using antibiotics in high concentrations, such as avoiding the risk of developing antibiotic-related dysbiosis [48].

\section{Materials and Methods}

\subsection{Bacterial Growth Conditions, Isolation, and Identification of Acinetobacter spp. Isolates}

In this study, three selected isolates of Acinetobacter spp. designated as Acinetobacter spp. isolate 1; Acinetobacter spp. isolate 2, and Acinetobacter spp. isolate 3 were collected from hospitalized patients having burns, wounds, and blood infections, respectively. The samples were initially inoculated on blood agar (HiMedia, Mumbai, India) and MacConkey agar (HiMedia, Mumbai, India). Then, the morphological features of the bacterial colonies were studied. After Gram staining, single suspected colonies (non-lactose fermenting colonies, non-hemolytic, and creamy colonies) were transferred onto MacConkey agar and incubated at $44{ }^{\circ} \mathrm{C}$ for $24 \mathrm{~h}$ under aerobic conditions to obtain a pure bacterial culture. Bacterial isolates were initially identified using certain biochemical tests, including IMViC tests, catalase, oxidase, urease production, and sugar fermentation in triple sugar iron (TSI) [49]. The identification of the selected Acinetobacter spp. isolates was confirmed by a VITEK 2 compact system (BioMerieux, Craponne, France), in which a GN-ID Card contains 64 biochemical tests used to identify Gram-negative bacterial species was manually loaded. According to the manufacturer's instructions (BioMerieux, Craponne, France), the next steps of bacterial species diagnosis in the VITEK system were performed automatically.

Bacillus subtilis KATMIRA1933 and Bacillus amyloliquefaciens B-1895 were inoculated into MRS medium (De Man, Rogosa, Sharpe, Becton Dickinson and Company, Sparks, MD, USA) and incubated under aerobic conditions at $37^{\circ} \mathrm{C}$ for $24 \mathrm{~h}$.

\subsection{Ethical Statement and Consent}

The samples were collected from patients according to the Institutional Ethical Clearance Committee No.1656 on 22 September 2020. These samples were processed and stored 
according to the Guiding Principles for Ethical Research issued by the University of Diyala, Baqubah, Iraq.

\subsection{Antibiogram Assay of the Selected Acinetobacter spp. Isolates and the Probiotic Bacillus Strains}

The antibiotic susceptibility of the selected Acinetobacter spp. isolates and the tested bacilli strains was evaluated using the Kirby-Bauer method, according to the CLSI guidelines [26]. Briefly, 3-5 colonies of bacterial growth (Acinetobacter spp. and Bacillus strains) were transferred by a sterile inoculating loop to a tube containing $5 \mathrm{~mL}$ of broth culture medium. Using a spectrophotometer (Molecular Diagnostics, Sunnyvale, CA, USA), the bacterial growth was diluted and adjusted to an optical density $\left(\mathrm{OD}_{630}\right)$ of 0.1 , which correlated with $10^{8} \mathrm{CFU} / \mathrm{mL}$. Then, $100 \mu \mathrm{L}$ aliquots of each bacterial suspension were streaked using a swab onto Muller-Hinton agar (MHA) in three directions.

The antibiotics were selected based on the recommendation of physicians as commonly prescribed antimicrobials for Acinetobacter infections. The tested antibiotic discs include amikacin $(30 \mu \mathrm{g})$, colistin (polymyxin E) $(25 \mu \mathrm{g})$, cefoxitin $(30 \mu \mathrm{g})$, cefotaxime $(30 \mu \mathrm{g})$, meropenem $(10 \mu \mathrm{g})$ and trimethoprim-sulfamethoxazole $(1.25 / 23.75 \mu \mathrm{g})$. These antibiotics were placed on the previously inoculated MHA with the selected Acinetobacter spp. isolates, and the agar plates were incubated aerobically at $37^{\circ} \mathrm{C}$ for $24 \mathrm{~h}$. The diameter of each zone of inhibition was measured in millimeters $(\mathrm{mm})$. Bacterial resistance and sensitivity to antibiotics were determined based on the standard chart approved by the CLSI. Table S1 (CLSI, 2020).

\subsection{Biofilm Formation Assay}

The biofilm formation assay was performed according to Ghellai et al. [50] with minor modifications. Briefly, $20 \mu \mathrm{L}$ of overnight bacterial growth was diluted into BHI supplemented by $1 \%$ glucose (BHIG) to achieve $10^{6} \mathrm{CFU} / \mathrm{mL}$ and inoculated into a flatbottom tissue culture 96-well microplate containing $180 \mu \mathrm{L}$ of BHIG. A negative control ( $200 \mu \mathrm{L}$ of BHIG only) was used in this experiment. The microplate was sealed and incubated at $37^{\circ} \mathrm{C}$ for $24 \mathrm{~h}$ under aerobic conditions. After incubation, the unattached bacterial cells were removed by pipetting, and the wells were washed twice with PBS ( $\mathrm{pH}$ 7.1). The microplate was dried at room temperature for $15 \mathrm{~min}$, and the biofilm was fixed by heating for $60 \mathrm{~min}$ at $60^{\circ} \mathrm{C}$ in the oven. Then, $100 \mu \mathrm{L}$ of crystal violet solution $(0.1 \%)$ was added to the treated wells and left for $20 \mathrm{~min}$. After that, the residue of crystal violet was removed, and each well was washed by PBS three times to remove the unbounded crystal violet dye. Then, $200 \mu \mathrm{L}$ of ethanol $95 \%$ was added to the wells, and the plate was then incubated at $4{ }^{\circ} \mathrm{C}$ for $30 \mathrm{~min}$ to solubilize the crystal violate-stained biofilm mass. The absorbance of the treated and the negative control wells was reported at $630 \mathrm{~nm}$ using a microplate reader.

Based on the absorbance, three categories of biofilm formers were identified according to Tang et al. [51]; low biofilm formers (LBF), intermediate biofilm formers (IBF), and high biofilm formers (HBF). When $\mathrm{OD}^{*} \leq{ }^{*} \mathrm{ODc}$ indicated non-biofilm, $\mathrm{ODc}<\mathrm{OD} \leq 2 \times \mathrm{ODc}=$ moderately biofilm producer, while $2 \times \mathrm{ODc}<\mathrm{OD}=$ strong biofilm producer.

* OD: mean optical density of biofilm mass stained with crystal violet; ODc: mean optical density of the negative control.

\subsection{Preparation of CFS of the Tested Probiotics}

The cell-free supernatants (CFS) of B. subtilis KATMIRA1933 and B. amyloliquefaciens B-1895 were prepared as previously described by Algburi et al. [38]. These strains were inoculated into MRS broth and incubated aerobically at $37^{\circ} \mathrm{C}$ for $24-36 \mathrm{~h}$. The bacterial cells were precipitated and removed using a centrifuge $\left(4480 \times \mathrm{g}\right.$ at $4{ }^{\circ} \mathrm{C}$ for $\left.30 \mathrm{~min}\right)$. The supernatants were sterilized using a $0.22 \mu \mathrm{m}$ polytetrafluoroethylene (PTFE) syringe filter (Fisherbrand ${ }^{\mathrm{TM}}$, Thermo Fisher Scientific, Waltham, MA, USA). The CFS was kept at $4{ }^{\circ} \mathrm{C}$ for less than 5 days before it was used. 


\subsection{Antibiotics Combination with CFS of Probiotics Using Disc Diffusion Method}

The antimicrobial combination in the disc was performed using the modified KirbyBauer method according to Algburi et al. [41]. Briefly, the overnight growth of the selected Acinetobacter spp. isolates in BHI broth was diluted and adjusted to $10^{8} \mathrm{CFU} / \mathrm{mL}$ using a spectrophotometer (Molecular Diagnostics, Sunnyvale, CA, USA). Then, the adjusted bacterial growth was streaked over the MHA plate in three directions. Each antibiotic disc was separately saturated with $20 \mu$ Lof CFS of the tested bacilli. Three types of discs were prepared in this assay: (i) antibiotic disc only, (ii) antibiotic disc saturated with the tested bacilli CFS, and (iii) a blank disc saturated with bacilli CFS only. A blank non-treated disc was used as a negative control. All discs were placed on the surface of MHA, which was previously inoculated with the isolated pathogen. The agar plates were left for $30 \mathrm{~min}$ until the antibiotic was diffused from the discs into the surrounding agar surface, and then incubated aerobically at $37^{\circ} \mathrm{C}$ for $24 \mathrm{~h}$. After incubation, the bacterial sensitivity and resistance to antimicrobials were identified by measurement of inhibition zones around the discs and according to a standard chart for antibiotic susceptibility testing.

\subsection{Coaggregation Test}

The coaggregation of the tested bacilli with the selected Acinetobacter spp. isolates was performed according to Algburi et al. [52] with some modifications. Briefly, the bacterial cultures were harvested from the planktonically grown cells incubated at $37^{\circ} \mathrm{C}$ by centrifugation $\left(4480 \times g, 23{ }^{\circ} \mathrm{C}, 15 \mathrm{~min}\right)$; the cells were then washed with sterile PBS three times. After the third wash, the harvested cells were re-suspended in PBS, and their optical density $\left(\mathrm{OD}_{630}\right)$ was adjusted to 0.25 . In a sterile tube, $2 \mathrm{~mL}$ of the washed bacilli cells were mixed with $2 \mathrm{~mL}$ of the selected Acinetobacter spp. growth. As controls, $4 \mathrm{~mL}$ of bacterial monoculture was added in separate tubes. The tubes were incubated aerobically at $37^{\circ} \mathrm{C}$, and the $\mathrm{OD}_{630}$ values were taken separately at 0,4 , and $24 \mathrm{~h}$. Based on the below equation described by Ledder et al. [53], the coaggregation percentages were calculated.

$$
\text { coaggregation } \%=\frac{x-y}{x} \times 100
$$

where $x$ is the $\mathrm{OD}_{630}$ value before incubation and $y$ is the $\mathrm{OD}_{630}$ value after incubation per-time point.

At 0,4 , and $24 \mathrm{~h}$ time points, samples of $5 \mu \mathrm{L}$ were transferred to a glass slide, stained with Gram staining, and observed for coaggregation score using a transmitted light microscope (Roth GmbH \& Co. KG, Karlsruhe, Germany). The bacterial interactions were examined using the $100 \times / 1.25$ oil objective. The Kopacam, NIS- Elements D3.0 software was used for photographing. The percentages of coaggregation were analyzed and scored with a system established by Algburi et al. [52], with 0 being the absence of coaggregation and 4 being an abundance of coaggregation. Each experiment was performed in duplicate.

\subsection{Minimum Inhibitory Concentration (MIC)}

MIC determination was performed according to Algburi et al. [54], with minor modifications. Briefly, the $100 \mathrm{mg}$ of polymyxin $\mathrm{E}$ was dissolved in $5 \mathrm{~mL}$ of sterile distilled water to obtain $20 \mathrm{mg} / \mathrm{mL}$ as a stock solution; $1 \mathrm{~mL}$ of stock solution was taken and transferred into $19 \mathrm{~mL}$ of BHI broth to obtain $1000 \mu \mathrm{g} / \mathrm{mL}$ as the primarily stock solution. A series of two-fold dilutions of antimicrobials (polymyxin E and the CFSs of the tested bacilli) were separately performed with fresh BHI broth into 96-well microplate, with a final volume of $100 \mu \mathrm{L}$. Then, $100 \mu \mathrm{L}$ of the diluted suspension of the selected Acinetobacter spp. isolates in $\mathrm{BHI}\left(10^{6} \mathrm{CFU} / \mathrm{mL}\right)$ was transferred into each well containing $100 \mu \mathrm{L}$ of pre-determined concentrations of both antimicrobials. The microplates were incubated under aerobic conditions for $24-36 \mathrm{~h}$ at $37^{\circ} \mathrm{C}$. The MICs were determined using a microplate reader (Molecular Diagnostics, Sunnyvale, CA, USA) at $\mathrm{OD}_{630}$. The MIC was defined according to the CLSI [26], as the lower concentration of antimicrobial cause bacterial growth inhibition with an OD reading $20 \%$ less than the positive control. 


\subsection{Determination of Minimal Biofilm Inhibitory Concentration (MBIC)}

The MBIC assay was performed as described in our previous study [54], with minor modifications. Briefly, the stock solution of polymyxin E $(1000 \mu \mathrm{g} / \mathrm{mL})$ was prepared in BHIG broth. The antibiotic and CFS of the tested bacilli were diluted two-fold with fresh BHIG into the 96-well tissue culture microplate broth to a final volume of $100 \mu \mathrm{L}$ in each well. Separately, the overnight cell culture of the selected Acinetobacter spp. isolates was diluted in BHIG broth to $10^{7} \mathrm{CFU} / \mathrm{mL}$. Then, $100 \mu \mathrm{L}$ as separately added into the wells containing pre-determined concentrations of polymyxin $\mathrm{E}$ and bacilli CFS. The microplate was incubated under aerobic conditions for $24-36 \mathrm{~h}$ at $37^{\circ} \mathrm{C}$. The non-adherent cells were transferred to a new 96-well microplate, and the absorbance of bacterial growth was evaluated using a microplate reader at $\mathrm{OD}_{630}$. The wells were then washed gently twice with $200 \mu \mathrm{L}$ of PBS. The biofilm was fixed by heating for $60 \mathrm{~min}$ at $60{ }^{\circ} \mathrm{C}$ and stained with crystal violet, as mentioned above. The absorbance measurement was made using a microplate reader at $630 \mathrm{~nm}$ to determine the MBIC.

\subsection{Checkerboard Assay for Antimicrobial Combinations}

To evaluate the antimicrobial potential of the selected bacilli CFSs in combination with polymyxin E against planktonic and biofilm cells of the selected Acinetobacter spp. strains, a checkerboard assay was performed following Algburi et al. [46] with minor modifications. Briefly, the $24 \mathrm{~h}$ growth of Acinetobacter spp. was diluted to achieve $10^{6} \mathrm{CFU} / \mathrm{mL}$. Each antimicrobial agent was diluted two-fold with BHI (to determine MIC) or with BHIG (to determine MBIC) into two separate 96-well microplates. Then, from each dilution of antimicrobial A (CFS of one bacilli strain), $50 \mu \mathrm{L}$ was taken and added horizontally over $50 \mu \mathrm{L}$ of each dilution of antimicrobial B (polymyxin E). Then, $100 \mu \mathrm{L}$ of the selected Acinetobacter spp. strains suspension $\left(10^{6} \mathrm{CFU} / \mathrm{mL}\right)$ was separately added to the pre-determined concentrations of antimicrobial combinations. A total of $200 \mu \mathrm{L}$ of the final bacterial suspension $\left(10^{6} \mathrm{CFU} / \mathrm{mL}\right)$ was added in duplicate, as a positive control. The MIC and MBIC of each antimicrobial combination were determined after $24 \mathrm{~h}$ of incubation. After incubation, the non-adherent cells' growth in the treated wells was evaluated using a microplate reader (Molecular Diagnostics, Sunnyvale, CA, USA) at $\mathrm{OD}_{630}$ to determine the MIC of the combinations of the antimicrobials. To determine the MBIC, the wells were gently washed three times with $200 \mu \mathrm{L}$ of PBS. As previously explained, the biofilm was fixed, stained with crystal violet, and the absorbance was measured at $630 \mathrm{~nm}$ using a microplate reader (Molecular Diagnostics, Sunnyvale, CA, USA) according to Algburi et al. [54]; isobolograms were used to analyze the nature of antimicrobial combinations or synergistic, antagonistic, or additive activity against the planktonic cells. The total fractional inhibitory concentrations index $(\Sigma F I C)$ was used to evaluate the anti-biofilm potential of antimicrobial combinations against the selected Acinetobacter spp. isolates.

\subsection{Checkerboard Assay, Data Analysis}

Isobolograms were used to compare the MIC values of each antimicrobial agent alone with its MIC values in combinations with other antimicrobial agents. Data were analyzed and explained as previously described by Turovskiy and Chikindas [55]. The $\Sigma$ FIC was calculated using the following equations:

$$
\begin{gathered}
\Sigma \mathrm{FIC}=\mathrm{FICA}+\mathrm{FICB} \\
\text { FICA }=(\mathrm{CA} / \mathrm{MICA}), \mathrm{FICB}=(\mathrm{CB} / \mathrm{MICB})
\end{gathered}
$$

where MICA and MICB are the MICs of antimicrobials A and B alone, respectively, and CA and $\mathrm{CB}$ are the concentrations of the antimicrobials in combination.

An FIC index of $<0.5$ indicates synergism, $>0.5$ to $<1$ indicates additive effects, $>1$ to $<2$ indifference, and $\geq 2$ antagonism [56]. 


\subsection{Statistical Analysis}

The data obtained in this study were sorted according to the graph pad prism V5 software. In this study, the two-way ANOVA test and Chi-square test were performed to analyze the effect of bacilli CFS and polymyxin $\mathrm{E}$ on bacterial growth. $p$ values of $<0.05$ were considered statistically significant. Sigma plot V11 software was used to generate the isobolograms for the antimicrobial combinations against the planktonic cells of the isolated Acinetobacter spp.

\section{Conclusions}

Acinetobacter spp., one of the most important pathogens of several hospital-acquired infections, showed high resistance to most tested antibiotics but was highly sensitive to polymyxin E. Our findings should attract researchers to implement a strict protocol to control such infections caused by XDR and MDR isolates of selected Acinetobacter spp. Strong biofilm formation by the majority of Acinetobacter spp. isolates is improving their colonization and antibiotic resistance. Probiotics and the natural antimicrobials they produce are good candidates for use as alternative agents for controlling biofilm-associated Acinetobacter spp. stains. Our data provide insight into the development of novel, safe, and effective antimicrobial and anti-biofilm agents to prevent biofilm-associated multidrug-resistant infections. It was reported that natural compounds produced by beneficial microbes can target bacterial cell envelopes, and as a result, they may facilitate antibiotics' activity and reduce the possibility of antibiotics resistance. The antimicrobial and anti-biofilm activities of polymyxin E were improved and showed synergism when combined with the CFS of the tested probiotic bacilli against planktonic and biofilm-associated cells of the selected Acinetobacter spp. isolates. Future in vivo studies are needed to clarify the mechanism (pharmacokinetic and pharmacodynamic) of polymyxins when combined with substances produced by probiotics to inhibit the biofilm of Acinetobacter spp. isolates and to ensure the safety of these antimicrobial interactions.

Supplementary Materials: The following are available online at https://www.mdpi.com/article/ 10.3390/pathogens10121574/s1. Table S1. The diameters of inhibition zones; interpretive standards for the selected Acinetobacter spp. strains according to (CLSI, 2020).

Author Contributions: Conceptualization, A.A. (Ammar Algburi) and A.A. (Alyaa Abdelhameed); methodology, M.A.-D. and A.A. (Ammar Algburi); software, M.A.-D.; validation, A.A. (Ammar Algburi), A.M.E. and A.A. (Alyaa Abdelhameed); formal analysis, M.A.-D. and A.A. (Ammar Algburi); investigation, M.A.-D.; Resources, M.S.M., A.M.E., D.V.R. and M.L.C.; data curation, A.A. (Ammar Algburi), M.L.C., M.S.M. and D.V.R.; writing-original draft preparation, M.A.-D. and A.A. (Ammar Algburi); writing — review and editing, A.A.(Ammar Algburi), M.L.C.; visualization, A.A. (Ammar Algburi), A.A. (Alyaa Abdelhameed), M.L.C., M.S.M. and D.V.R.; supervision, A.A. (Ammar Algburi) and A.A. (Alyaa Abdelhameed); project administration, A.A. (Ammar Algburi), M.L.C. and A.M.E.; funding acquisition, M.L.C. and D.V.R. All authors have read and agreed to the published version of the manuscript.

Funding: M.S.M., D.V.R. and M.L.C. acknowledge the support of the Ministry of Science and Higher Education of the Russian Federation (contract number 075-15-2019-1880 and state task number 01201354245). D.V.R. was supported by the Russian Federation President Grant for Young Scientists (MK-1700.2021.5, agreement number 075-15-2021-179).

Institutional Review Board Statement: Not applicable.

Informed Consent Statement: Not applicable.

Data Availability Statement: Not applicable.

Acknowledgments: The authors would like to acknowledge the University of Diyala and the General Teaching Hospital in Baqubah, Iraq, for providing free access to the equipment and facilities required in this study.

Conflicts of Interest: The authors declare no conflict of interest. 


\section{References}

1. Martín-Aspas, A.; Guerrero-Sánchez, F.M.; García-Colchero, F.; Rodríguez-Roca, S.; Girón-González, J.-A. Differential characteristics of Acinetobacter baumannii colonization and infection: Risk factors, clinical picture, and mortality. Infect. Drug Resist. 2018, 11, 861-872. [CrossRef]

2. Morris, F.; Dexter, C.; Kostoulias, X.; Uddin, M.I.; Peleg, A.Y. The Mechanisms of Disease Caused by Acinetobacter baumannii. Front. Microbiol. 2019, 10, 1601. [CrossRef] [PubMed]

3. Shin, D.-S.; Eom, Y.-B. Antimicrobial and anti-biofilm activities of Clostridium butyricum supernatant against Acinetobacter baumannii. Arch. Microbiol. 2020, 202, 1059-1068. [CrossRef]

4. Rezaee, P.; Hamzeh, A.; Mohammadi, M. Acinetobacter baumannii antibiotics resistance in Iran. J. Bacteriol. Mycol. Open Access 2019, 7, 159-162. [CrossRef]

5. Raheem, A.; Hussain, S.S.; Essa, R.H.; Atia, A.-J. The effect of new hydantoin derivative (compound) on Acinetobacter baumannii biofilm formation isolated from clinical sources. J. Univ. Babylon Pure App. Sci. 2018, 26, 71-79.

6. Asif, M.; Alvi, I.A.; Rehman, S.U. Insight into Acinetobacter baumannii: Pathogenesis, global resistance, mechanisms of resistance, treatment options, and alternative modalities. Infect. Drug Resist. 2018, 11, 1249-1260. [CrossRef]

7. Pacheco, T.; Bustos, R.-H.; González, D.; Garzón, V.; García, J.-C.; Ramírez, D. An Approach to Measuring Colistin Plasma Levels Regarding the Treatment of Multidrug-Resistant Bacterial Infection. Antibiotics 2019, 8, 100. [CrossRef] [PubMed]

8. Farshadzadeh, Z.; Taheri, B.; Rahimi, S.; Shoja, S.; Pourhajibagher, M.; Haghighi, M.A.; Bahador, A. Growth Rate and Biofilm Formation Ability of Clinical and Laboratory-Evolved Colistin-Resistant Strains of Acinetobacter baumannii. Front. Microbiol. 2018, 9, 153. [CrossRef]

9. Mosca, A.; Dalfino, L.; Romanelli, F.; Stolfa, S.; Prete, R.D.; Santacroce, L. Effectiveness of colistin with rifampicin and meropenem against colistin-resistant Acinetobacter baumannii strains: An in vitro study. Pharmacophore 2020, 11, 1-6.

10. Isayenko, O.Y.; Knysh, O.V.; Kotsar, O.V.; Ryzhkova, T.N.; Dyukareva, G.I. Simultaneous and sequential influence of metabolite complexes of Lactobacillus rhamnosus and Saccharomyces boulardii and antibiotics against poly-resistant Gram-negative bacteria. Regul. Mech. Biosyst. 2020, 11, 139-145. [CrossRef]

11. Food and Agriculture Organization/World Health Organization Expert Consultation (FAO/WHO). Evaluation of Health and Nutritional Properties of Probiotics in Food including Powder Milk with Live Lactic Acid Bacteria; [cited 2005 September 8]; Food and Agriculture Organization of the United Nations and World Health Organization: Córdoba, Argentina, 2001. Available online: https:/ / www.fao.org/3/a0512e/a0512e.pdf (accessed on 1 October 2021).

12. Hager, C.L.; Isham, N.; Schrom, K.P.; Chandra, J.; McCormick, T.; Miyagi, M.; Ghannoum, M.A. Effects of a Novel Probiotic Combination on Pathogenic Bacterial-Fungal Polymicrobial Biofilms. mBio 2019, 10, e00338-19. [CrossRef] [PubMed]

13. Karacaer, F.; Hamed, I.; Özogul, F.; Glew, R.H.; Özcengiz, D. The function of probiotics on the treatment of ventilator-associated pneumonia (VAP): Facts and gaps. J. Med. Microbiol. 2017, 66, 1275-1285. [CrossRef] [PubMed]

14. Wang, L.; Wang, L. Acinetobacter baumannii biofilm resistance mechanisms and prevention and control of progress. New Century Sci. Press. 2016, 3, 22-26. [CrossRef]

15. Hadid, M.A. Evaluating the Effects of Probiotics and Vinegars on Bacteria Isolated from Burns and Wounds Infections. Master's Thesis, College of Science, Al-Nahrain University, Baghdad, Iraq, 2015.

16. AL-Dahlaki, S.M.M. Molecular Detection and Gene Expression for Hcpandblaoxa-51 genes in Acinetobacter baumannii Isolated from Different Clinical Sources. Master's Thesis, College of Science, University of Diyala, Baghdad, Iraq, 2020.

17. Raut, S.; Rijal, K.R.; Khatiwada, S.; Karna, S.; Khanal, R.; Adhikari, J.; Adhikari, B. Trend and characteristics of Acinetobacter baumannii infections in patients attending universal college of medical sciences, Bhairahawa, Western Nepal: A Longitudinal Study of 2018. Infect. Drug Resist. 2020, 13, 1631-1641. [CrossRef]

18. Pal, N.; Sujatha, R.; Kumar, A. Phenotypic and genotypic identification of Acinetobacter baumannii with special reference to blaoxa-51 Like gene and its antimicrobial susceptibility pattern from intensive care uniteS in Kanpur. Int. J. Contemp. Med. Res. 2017, 4, 1154-1158.

19. Rahimi, S.; Farshadzadeh, Z.; Taheri, B.; Mohammadi, M.; Haghighi, M.-A.; Bahador, A. The Relationship Between Antibiotic Resistance Phenotypes and Biofilm Formation Capacity in Clinical Isolates of Acinetobacter baumannii. Jundishapur J. Microbiol. 2018, 11, e74315. [CrossRef]

20. Nhu, N.T.K.; Riordan, D.W.; Nhu, T.D.H.; Thanh, D.P.; Thwaites, G.; Lan, N.P.H.; Wren, B.W.; Baker, S.; A Stabler, R. The induction and identification of novel Colistin resistance mutations in Acinetobacter baumannii and their implications. Sci. Rep. 2016, 6, 28291. [CrossRef]

21. Maleki, M.H.; Sekawi, Z.; Soroush, S.; Azizi-Jalilian, F.; Asadollahi, K.; Mohammadi, S.; Emaneini, M.; Taherikalani, M. Phenotypic and genotypic characteristics of tetracycline resistant Acinetobacter baumannii isolates from nosocomial infections at Tehran hospitals. Iranian J. Basic Med. Sci. 2014, 17, 21-26. [CrossRef]

22. Almasaudi, S.B. Acinetobacter spp. as nosocomial pathogens: Epidemiology and resistance features. Saudi J. Biol. Sci. 2016, 25, 586-596. [CrossRef]

23. Taitt, C.R.; Leski, T.; Stockelman, M.G.; Craft, D.W.; Zurawski, D.V.; Kirkup, B.; Vora, G.J. Antimicrobial Resistance Determinants in Acinetobacter baumannii Isolates Taken from Military Treatment Facilities. Antimicrob. Agents Chemother. 2013, 58, 767-781. [CrossRef] 
24. Ugolotti, E.; Di Marco, E.; Bandettini, R.; Tripodi, G.; Biassoni, R. The whole genome sequencing of Acinetobacter-calcoaceticusbaumannii complex strains involved in suspected outbreak in an intensive care unit of a pediatric hospital. J. Hosp. Adm. 2016, 5, 81. [CrossRef]

25. Moubareck, C.; Halat, D. Insights into Acinetobacterbaumannii: A review of microbiological, virulence, and resistance traits in a threatening nosocomial pathogen. Antibiotics 2020, 9, 119. [CrossRef]

26. Clinical and Laboratory Standards Institute (CLSI). Performance Standards for Antimicrobial Susceptibility Testing, 27th ed.; CLSI: Wayne, PA, USA, 2020.

27. Magiorakos, A.P.; Srinivasan, A.; Carey, R.B.; Carmeli, Y.; Falagas, M.E.; Giske, C.G.; Harbarth, S.; Hindler, J.F.; Kahlmeter, G.; Olsson-Liljequist, B.; et al. Multidrug resistant, extensively drug resistant, and pan drug resistant bacteria: An international expert proposal for interim standard definitions for acquired resistance. Clin. Microbiol. Infect. 2011, 18, 268-281. [CrossRef]

28. Pfalzgraff, A.; Brandenburg, K.; Weindl, G. Antimicrobial Peptides and Their Therapeutic Potential for Bacterial Skin Infections and Wounds. Front. Pharmacol. 2018, 9, 281. [CrossRef]

29. Bahador, A.; Raoo An, R.; Farshadzadeh, Z.; Beitollahi, L.; Khaledi, A.; Rahimi, S.; Mokhtaran, M.; Tavana, A.M.; Esmaeili, D. The prevalence of IS Aba 1 and IS Aba 4 in Acinetobacter baumannii species of different international clone lineages among patients with burning in Tehran, Iran. Jundishapur J. Microbiol. 2015, 8, e17167. [CrossRef] [PubMed]

30. Runci, F.; Bonchi, C.; Frangipani, E.; Visaggio, D.; Visca, P. Acinetobacter baumannii Biofilm Formation in Human Serum and Disruption by Gallium. Antimicrob. Agents Chemother. 2017, 61, e01563-16. [CrossRef] [PubMed]

31. Eze, E.C.; Chenia, H.Y.; El Zowalaty, M.E. Acinetobacter baumannii biofilms: Effects of physicochemical factors, virulence, antibiotic resistance determinants, gene regulation, and future antimicrobial treatments. Infect. Drug Resist. 2018, 11, 2277-2299. [CrossRef]

32. Sato, Y.; Unno, Y.; Ubagai, T.; Ono, Y. Sub-minimum inhibitory concentrations of colistin and polymyxin B promote Acinetobacter baumannii biofilm formation. PLoS ONE 2018, 13, e0194556. [CrossRef] [PubMed]

33. Lin, M.-F.; Lin, Y.-Y.; Lan, C.-Y. Characterization of biofilm production in different strains of Acinetobacter baumannii and the effects of chemical compounds on biofilm formation. PeerJ 2020, 8, e9020. [CrossRef]

34. Efremenkova, O.; Gabrielyan, N.; Malanicheva, I.; Demiankova, M.; Efimenko, T.; Rogozhin, E.; Sharapchenko, S.; Krupenio, T.; Davydov, D.; Kornilov, M. Antimicrobial properties of the probiotic strain Bacillus subtilis 534. Int. Arch. Med. Microbiol. 2019, 2, 119.

35. Soltan, M.M.; Davoodabadi, A.; Abdi, M.; Hajiabdolbaghi, M.; SharifiYazdi, M.K.; Douraghi, M.; TabatabaeiBafghi, S.M. Inhibitory effect of Lactobacillus plantarum and Lb. fermentum isolated from the faeces of healthy infants against non fermentative bacteria causing nosocomial infections. New Microb. New Infect. 2017, 15, 9-13. [CrossRef] [PubMed]

36. Lashin, G.M.A.; Tohamy, E.Y.; Askora, A.A.; El-Zahraa Mahmoud, F. Use of probiotic acid bacteria for the control of multidrug resistant bacterial isolated from clinical infections. Bull. Fac. Sci. Zagazig Univ. 2017, 39, 61-81. [CrossRef]

37. Kumariya, R.; Garsa, A.K.; Rajput, Y.; Sood, S.; Akhtar, N.; Patel, S. Bacteriocins: Classification, synthesis, mechanism of action and resistance development in food spoilage causing bacteria. Microb. Pathog. 2019, 128, 171-177. [CrossRef] [PubMed]

38. AlGburi, A.; Alazzawi, S.A.; Al-Ezzy, A.I.A.; Weeks, R.; Chistyakov, V.; Chikindas, M.L. Potential Probiotics Bacillus subtilis KATMIRA1933 and Bacillus amyloliquefaciens B-1895 Co-Aggregate with Clinical Isolates of Proteus mirabilis and Prevent Biofilm Formation. Probiotics Antimicrob. Proteins 2020, 12, 1471-1483. [CrossRef] [PubMed]

39. Zamani, H.; Rahbar, S.; Garakoui, S.R.; Sahebi, A.A.; Jafari, H.; Microbiology, S.O.P.C.S.O. Antibiofilm potential of Lactobacillus plantarum spp. cell free supernatant (CFS) against multidrug resistant bacterial pathogens. Pharm. Biomed. Res. 2017, 3, 39-44. [CrossRef]

40. Chapot-Chartier, M.P.; Kulakauskas, S. Cell wall structure and function in lactic acid bacteria. Microb. Cell Factories 2014, 13, S9. [CrossRef]

41. Algburi, A.; Al-Hasani, H.M.; Ismael, T.K.; Abdelhameed, A.; Weeks, R.; Ermakov, A.M.; Chikindas, M.L. Antimicrobial Activity of Bacillus subtilis KATMIRA1933 and Bacillus amyloliquefaciens B-1895 Against Staphylococcus aureus Biofilms Isolated from Wound Infection. Probiotics Antimicrob. Proteins 2020, 13, 125-134. [CrossRef] [PubMed]

42. Mathur, H.; Field, D.; Rea, M.C.; Cotter, P.; Hill, C.; Ross, R.P. Fighting biofilms with lantibiotics and other groups of bacteriocins. Npj Biofilms Microbiomes 2018, 4, 9. [CrossRef] [PubMed]

43. Fernandes, M.S.M.; Lourenço, M.L.M.C.; Vasconcelos, B.M.; Carneiro, V.A. Probiotics Lactobacillus strains: A promising alternative therapy against to biofilm-forming enteropathogenicbacteria? Afr. J. Microbiol. Res. 2019, 13, 544-551.

44. Isayenko, O.Y. Synergistic activity of filtrates of Lactobacillus rhamnosus and Saccharomyces boulardii and antibacterial preparations against Corynebacterium spp. Regul. Mech. Biosyst. 2019, 10, 445-456. [CrossRef]

45. Cavera, V.L.; Volski, A.; Chikindas, M.L. The Natural Antimicrobial Subtilosin A Synergizes with Lauramide Arginine Ethyl Ester (LAE), $\varepsilon$-Poly-l-lysine (Polylysine), Clindamycin Phosphate and Metronidazole, Against the Vaginal Pathogen Gardnerella vaginalis. Probiotics Antimicrob. Proteins 2015, 7, 164-171. [CrossRef]

46. Al-Gburi, A.; Volski, A.; Chikindas, M.L. Natural antimicrobials subtilosin and lauramide arginine ethyl ester synergize with conventional antibiotics clindamycin and metronidazole against biofilms of Gardnerella vaginalis but not against biofilms of healthy vaginal lactobacilli. Pathog. Dis. 2015, 73, ftv018. [CrossRef]

47. Karlyshev, A.V.; Melnikov, V.G.; Chistyakov, V.A.; Masood, N.; Jackson, E.; Moore, K.; Farbos, A.; Paszkiewicz, K.; Dickins, B.; McNally, A.; et al. Draft Genome Sequence of Bacillus amyloliquefaciens B-1895. Genome Announc. 2014, 2, e00585-14. [CrossRef]

48. Rowles, H.L. How are Probiotics Affected by Antibiotics? Ann. Clin. Lab. Res. 2017, 5, 2. [CrossRef] 
49. Cappuccino, J.G.; Welsh, C.T. Microbiology: A Laboratory Manual, 11th ed.; Pearson Education: London, UK, 2018.

50. Lotfi, G.; Hassaine, H.; Klouche, N.; Khadir, A.; Aissaoui, N.; Nas, F.; Zingg, W. Detection of biofilm formation of a collection of fifty strains of Staphylococcus aureus isolated in Algeria at the University Hospital of Tlemcen. J. Bacteriol. Res. 2014, 6, 1-6. [CrossRef]

51. Tang, J.; Kang, M.; Chen, H.; Shi, X.; Zhou, R.; Chen, J.; Du, Y. The staphylococcal nuclease prevents biofilm formation in Staphylococcus aureus and other biofilm-forming bacteria. Sci. China Life Sci. 2011, 54, 863-869. [CrossRef] [PubMed]

52. Al-Gburi, A.; Volski, A.; Cugini, C.; Walsh, E.M.; Chistyakov, V.A.; Mazanko, M.S.; Bren, A.B.; Dicks, L.M.T.; Chikindas, M.L. Safety Properties and Probiotic Potential of Bacillus subtilis KATMIRA1933 and Bacillus amyloliquefaciens B-1895. Adv. Microbiol. 2016, 6, 432-452. [CrossRef]

53. Ledder, R.G.; Timperley, A.S.; Friswell, M.K.; Macfarlane, S.; McBain, A.J. Coaggregation between and among human intestinal and oral bacteria. FEMS Microbiol. Ecol. 2008, 66, 630-636. [CrossRef] [PubMed]

54. Algburi, A.; Zhang, Y.; Weeks, R.; Comito, N.; Zehm, S.; Pinto, J.; Uhrich, K.E.; Chikindas, M.L. Gemini Cationic Amphiphiles Control Biofilm Formation by Bacterial Vaginosis Pathogens. Antimicrob. Agents Chemother. 2017, 61, e00650-17. [CrossRef] [PubMed]

55. Turovskiy, Y.; Chikindas, M.L. Zinc Lactate and Sapindin Act Synergistically with Lactocin 160 Against Gardnerella vaginalis. Probiotics Antimicrob. Proteins 2011, 3, 144-149. [CrossRef]

56. European Committee for Antimicrobial Susceptibility Testing (EUCAST) of the European Society of Clinical Microbiology and Infectious Diseases (ESCMID). Terminology relating to methods for the determination of susceptibility of bacteria to antimicrobial agents. Clin. Microbiol. Infect. 2000, 6, 503-508. [CrossRef] [PubMed] 